\title{
Kültürel Değerlere Duyarlı Öğretmen Özelliklerinin Sıralama Yargılarıyla Ölçeklenmesi
}

\author{
Gürkan SARIDAŞ $\quad$ Funda NAYİ***
}

• Geliş Tarihi: 17.11.2020 • Kabul Tarihi: 23.04.2021 • Çevrimiçi Yayın Tarihi: 23.04.2021

\section{$\ddot{\mathbf{O} z}$}

Kültürel değerlere duyarlı eğitim anlayışının ortaya çıkması öğretmenlere yeni roller yüklemiş, öğretmenlerin geleneksel rollerden çıkarak kültürel farklılığı eğitim ortamında bütünleştiren bir rol alması önem kazanmıştır. Bu noktada kültürel değerlere duyarlı öğretmenlerin özelliklerinin ne olması gerektiği ve eğitim öğretim sürecindeki öneminin ortaya çıkarılmasının önemli olduğu düşünülmektedir. Araştırmanın amacı kültürel değerlere duyarlı eğitim uygulamaları kapsamında öğretmen özelliklerinin ortaya konulması olarak belirlenmiştir. Araştırma üç aşamadan oluşmaktadır. Birinci ve ikinci aşamada kültürel değerlere duyarlı eğitim uygulamaları kapsamında öğretmen özelliklerinin ne olduğu araştırılmış, üçüncü aşamada ise bu özellikler sıralama yargılarına dayalı ölçekleme yöntemleri ile karşılaştırılmıştır. Araştırmanın verileri 2019-2020 öğretim yılında devlet okullarında görev yapan 266 öğretmenden toplanmıştır. Araştırmada elde edilen veriler sıralama yargılarıyla ölçekleme yöntemi ile analiz edilmiştir. Elde edilen bulgular sonucunda kültürel değerlere duyarlı öğretmen özelliklerinin yaşamında demokratik olma, öğrencilerin farklı olduğunu düşünme, eğitim öğretim sürecinde sabırlı olma, öğrencinin geçmiş yaşantısını bilme, yenilikçi bakış açısına sahip olma, mesleki gelişimine önem verme, sevgi dolu yaşam sürme eğiliminde olma, herhangi bir bireye ön yargılı olmama, evrensel değerlere sahip olma ve çevresindeki kişilere karşı anlayışı olma olarak sıralandığı görülmüştür. Araştırmada elde edilen bulgular kapsamında belirlenen özelliklerin öğretmenlerde hizmetiçi eğitim yoluyla, öğretmen adaylarında müfredat aracılığı ile kazandırılması, öğretmenlerin kültürel değerlere duyarlı eğitim uygulamaları noktasında bilinçlendirilmesi önerilmiştir.

Anahtar sözcükler: kültürel değerlere duyarlı öğretmen, demokratik olma, öğrencinin kültürünü tanıma, sıralama yargılarına dayalı ölçekleme.

\section{Atıf:}

Sarıdaş, G. ve Nayir, F. (2021). Kültürel değerlere duyarlı öğretmen özelliklerinin sıralama yargılarıyla ölçeklenmesi. Pamukkale Üniversitesi Eğitim Fakültesi Dergisi, 53, 355377.doi:10.9779.pauefd.827009

\footnotetext{
* Milli Eğitim Bakanlığı, theapeiron@gmail.com, ORCID : 0000-0002-7989-2130

** Pamukkale Üniversitesi, fnayir09@gmail.com, ORCID : 0000-0002-9313-4942
} 


\section{Giriș}

Günümüzde farklı kültürlerin bir arada yaşamasının artmasıyla eğitim alanında da ihtiyaçlar ve beklentiler değişmeye başlamıştır. Buna göre öğretmenlerin eğitim öğretim sürecinde kültürel farklılıklara duyarlı olması ve bu farklılıkları önemsemesi önem taşımaktadır. Öğretmenlik kendi içinde değerler içeren bir meslektir. Bu değerler öğretmenlik mesleğinin kodlarını oluşturmakta başka bir deyişle öğretmenlerde olması gereken özellikleri belirlemektedir. Bu noktada kültürel değerlere duyarlı öğretmenlerin özelliklerinin ne olması gerektiği ve bu özelliklerin eğitim öğretim sürecindeki öneminin ortaya çıkarılmasının önemli olduğu düşünülmektedir.

Öğretmenler, toplumdaki kişilerin özelliklerini geliştirmeye ve çeşitli özellikler kazandırmaya odaklanır. Çünkü insan üzerindeki bu özellikler, toplumdaki bireylerin önemli durumları bilmesini, tercihlerini ne yönde kullanması gerektiğini, yaşam standartlarını belirler. $\mathrm{Bu}$ özellikleri geliştirmenin amacı bireyin toplum içindeki yaşantısı ile eğitimini düzenlemek ve topluma katkı sağlayacağı verimliliği artırmaktır (Akbaş, 2008; Çelikten, Şanal, ve Yeni, 2005). Milli Eğitim Temel Kanununda (MEB, 1973) yer alan genel amaçlar (Md. 2) incelendiğinde Atatürkçü, vatansever, sağlıklı, milletine bağl1, demokratik, bilimsel düşünen, görev ve sorumluluklarını bilen gibi toplumdaki kişilere kazandırılması gereken özellikler karşımıza çıkmaktadır. Bu özellikler öğretmenler tarafından öğrencilere geniş bir yelpazede aktarılırken daha dar anlamda öğretmenler de çeşitli özelliklere sahiptir. Öğretmenlerin sahip olması gereken özellikler Millî Eğitim Bakanlığı tarafından kişisel ve mesleki olarak iki grupta incelenmektedir. Bu özellikler incelendiğinde açık görüşlü, öğrenci beklentilerini dikkate alan, farklılıklara önem veren, yenilikçi, araştırmacı, işbirlikçi, sabırlı, alan ve meslek bilgisine sahip, öğretim ortamını uygun bir şekilde düzenleyebilen, genel kültür sahibi (Çelikten, Şanal, ve Yeni, 2005; Şahin, 2011) gibi özellikler ortaya çıkmaktadır. Bu noktada öğretmen özelliklerinin demokratik olma, bireysel farklılıklar önem veren, mesleğine bağl1, mesleki gelişimine önem veren özellikler olarak ortaya çıktığını söylemek mümkündür.

Araştırma kapsamında ise kültürel değerlere duyarlı eğitim uygulamalarına yönelik öğretmen özelliklerine odaklanılmıştır. Kültürel değerlere duyarlı eğitim, kültürel olarak farklılık gösteren öğrencilerin kültürel özelliklerini, deneyimlerini, bakış açılarını kullanarak öğrencilerin daha etkin bir şekilde öğrenmesi için kanallar oluşturmak (Gay, 2002) şeklinde tanımlanabilir. Tanımdan da anlaşılabileceği gibi kültürel değerlerle duyarlı eğitim uygulamalarının odak noktası kültürel değerlerin bir araç olarak kullanılmasıdır. Bu noktada 
kültürel değerlere duyarlı eğitim uygulamalarını gerçekleştirecek öğretmenlerin çeşitli özelliklere sahip olması gerekmektedir. Bu özellikler kültürel okuryazar olmak, öğretim yöntem ve tekniklerini sürekli güncellemek, sınıfın özgüveni yüksek bir şekilde derse katılımını sağlamak, sınıftaki herkesin farklılıklara karşı saygılı olmasını sağlamak, öğretmen temelli müfredat geliştirme çalışmalarını gerçekleştirmek, öğrencilerinin eleştirel düşünme becerisini geliştirmek, evrensel değerler etrafından toplanılmasını sağlamaktır (Pewewardy ve Hammer, 2003).

Kültürel değerlere duyarlı öğretmenler öğretmenlerin tek otorite olduğu bir anlayışını reddederek öğrenme sürecini kolaylaştıran ve öğrenciler için rehber olan bir anlayış1 benimser (Gay, 2002a; Ladson-Billings, 2009; Banks ve Banks, 1995). Bu öğretmenler öğrencilerin sahip olduğu potansiyellerini ortaya çıkararak sınıfta ortak bir kültür yaratır ve anlayışl1, demokratik ve tarafsız davranmaya özen gösterir (Ladson-Billings, 1999). Grup çalışması ve işbirlikli öğrenmeyi ön plana çıkaran kültürel değerlere duyarlı öğretmenler (Villegas ve Lucas, 2002; Nieto, 2002) öğrencilerden beklentileri yüksek tutarak onların akademik gelişimi için uğraşırlar (Villegas ve Lucas, 2002). Bu öğretmenler, öğrencilerin öğrenmesine katkı sağlamak için aileleriyle iletişim kurar (Jarosinski, 2018; Lazar, Edwards ve McMillon, 2012) ve öğrencilerin kültürel farklılıklarını öğretim sürecine dahil ederler (Gay, 2018). Bununla birlikte kültürel değerlere duyarlı öğretmenler hem kendi kültürel geçmişlerinin hem de öğrencilerin kültürel geçmişlerinin farkında olan öğretmenlerdir (Weinstein, Curran ve Tomlinson-Clarke, 2003; Weinstein, Tomlinson-Clarke ve Curran ,2004). Görüldüğ̈̈ gibi kültürel değerlere duyarlı öğretmenler kültürel farklılıkları öğretim sürecine bir katkı olarak görmekte, her öğrenciye değer vermekte ve her öğrencinin kültürel birikimlerine saygı duymaktadırlar (Nayir, 2019). Bu kapsamda incelendiğinde öğretmenin kendi kültürünün farklında bir şekilde kendi kültürünü sorgulayarak önyargılardan arınmış bir şekilde akademik ve sosyal gelişimi destekleyen çalışmalar yapması önemlidir. Kültürel değerlere duyarlı öğretmen, farklı rol ve sorumluluklara sahip, geleneksek öğretmen özelliklerinin dışında, öğrencilerin geçmişini bilen ve öğrencilerin sahip oldukları farklılıkları zenginlik olarak görüp, eleştirel bir bakış açısıyla eğitim ortamını düzenleyen ve tüm öğrencilerinin eşit düzeyde bu ortamdan yararlanmasına olanak sağlayan öğretmen olarak tanımlanabilir. Dolayısıyla kültürel değerlere duyarlı öğretmeni tam olarak tanımlayabilmek için belirli özelliklerin belirlenmesi ve bu özelliklerin önem sırasının ortaya konması önemlidir. 
Kültürel değerlere duyarlı eğitim Türkiye için son yıllarda araştırılmaya başlanmış bir kavramdır. Halbuki Türkiye UNHCR (2019) verilerin göre Türkiye'de 3,6 milyon Suriye, 170 bin Afganistan, 142 bin Irak, 39 bin İran, 5 bin 7 yüz Somali ve 11 bin 7 yüz diğer ülke vatandaşı göçmen olarak bulunmaktadır. Kültürel farklılıkların göçlerdeki artış ile Türkiye'de daha fazla gözlenmeye başlandığı dolayısıyla kültürel değerlere duyarlı eğitim uygulamalarına daha fazla ihtiyaç olduğu söylenebilir. Bu noktada kültürel değerlere duyarlı eğitim uygulamalarını yürütecek öğretmenlerin özelliklerini belirlemeye ihtiyaç vardır. Türkiye'de öğretmenlerin kültürel değerlere duyarlı eğitim ve uygulamalarına ilişkin yapılan çalışmalarda kültürel değerlere duyarlı eğitime ilişkin hazırbulunuşluk (Karataş ve Oral, 2017) kültürel değerlere duyarlı eğitim anlayışı (Kotluk ve Kocakaya, 2018a), öğretmenlerin kültürel değerlere duyarlı eğitime ilişkin görüşleri (Kotluk ve Kocakaya, 2018b; Kotluk ve Kocakaya, 2017) ve kültürel değerlere duyarlı öğretmen rolleri (Nayir, 2019) ve kültürel değerlere duyarlı öğretmen (Karataş, 2020) konularına değinildiği görülmektedir. Bu çalışmalarda özellikle Nayir (2019) ve Karataş (2020) kültürel değerlere duyarlı öğretmenlerin rollerini ve bu öğretmenlerin kültürel değerlere duyarlılığa sahip olma durumlarını ortaya çıkarmaya çalışılmıştır. Ancak kültürel değerlere duyarlı öğretmenin sahip olması gereken en önemli özelliklerin ne olduğu incelenmemiştir. Araştırma, Millî Eğitim Bakanlığı (MEB) tarafından yapılacak hizmetiçi eğitimler aracılığı ile öğretmenlerin hangi becerilerinin geliştirilmesi gerektiği, Yüksek Öğretim Kurulu (YÖK) tarafindan ise hizmet öncesi eğitimde öğretmen adaylarının hangi becerilerinin geliştirilmesi gerektiği noktasında bilgi vereceğinden ilgili literatüre katkı sağlayacaktır. İlgili literatür incelendiğinde kültürel değerlere duyarlı öğretmen özelliklerinin belirlenmesinde bir netlik kazanılmadı̆̆ı gözlenmektedir. Bu nedenle araştırma kapsamında elde edilecek sonuçlar literatüre katkı sağlayacağı gibi aynı zamanda öğretmenlerin ve öğretmen adaylarının kazanması gereken değerleri de ortaya çıkarması açısından önemlidir. $\mathrm{Bu}$ araştırmanın amacı kültürel değerlere duyarlı eğitim uygulamaları kapsamında öğretmen özelliklerinin ortaya konulması olarak belirlenmiştir. Bu amaç doğrultusunda şu alt amaçlar belirlenmiştir:

- Kültürel değerlere duyarlı eğitim uygulamaları kapsamında öğretmen özellikleri nelerdir?

- Kültürel değerlere duyarlı eğitim uygulamaları kapsamında bu özelliklerin önem siras1 nedir? 


\section{Yöntem}

\section{Araștırmanın Modeli}

Araştırma, genel tarama modelinde nicel bir çalışmadır. Tarama modelleri evren hakkında genel bir yargıya varmak amacıyla evrenin tümü ya da ondan alınacak bir grup üzerinden yapılan araştırmaları kapsar (Karasar, 2000). Bu araştırmada da kültürel değerlere duyarlı öğretmen özelliklerinin nasıl bir sıralamaya sahip olduğu öğretmen görüşlerine dayalı olarak ortaya çıkarılmaya çalışıldığından tarama deseninde bir araştırma olduğu söylenebilir. Araştırma üç aşamada gerçekleştirilmiştir. Araştırmaya ait üç aşama Şekil 1'de verilmiştir.

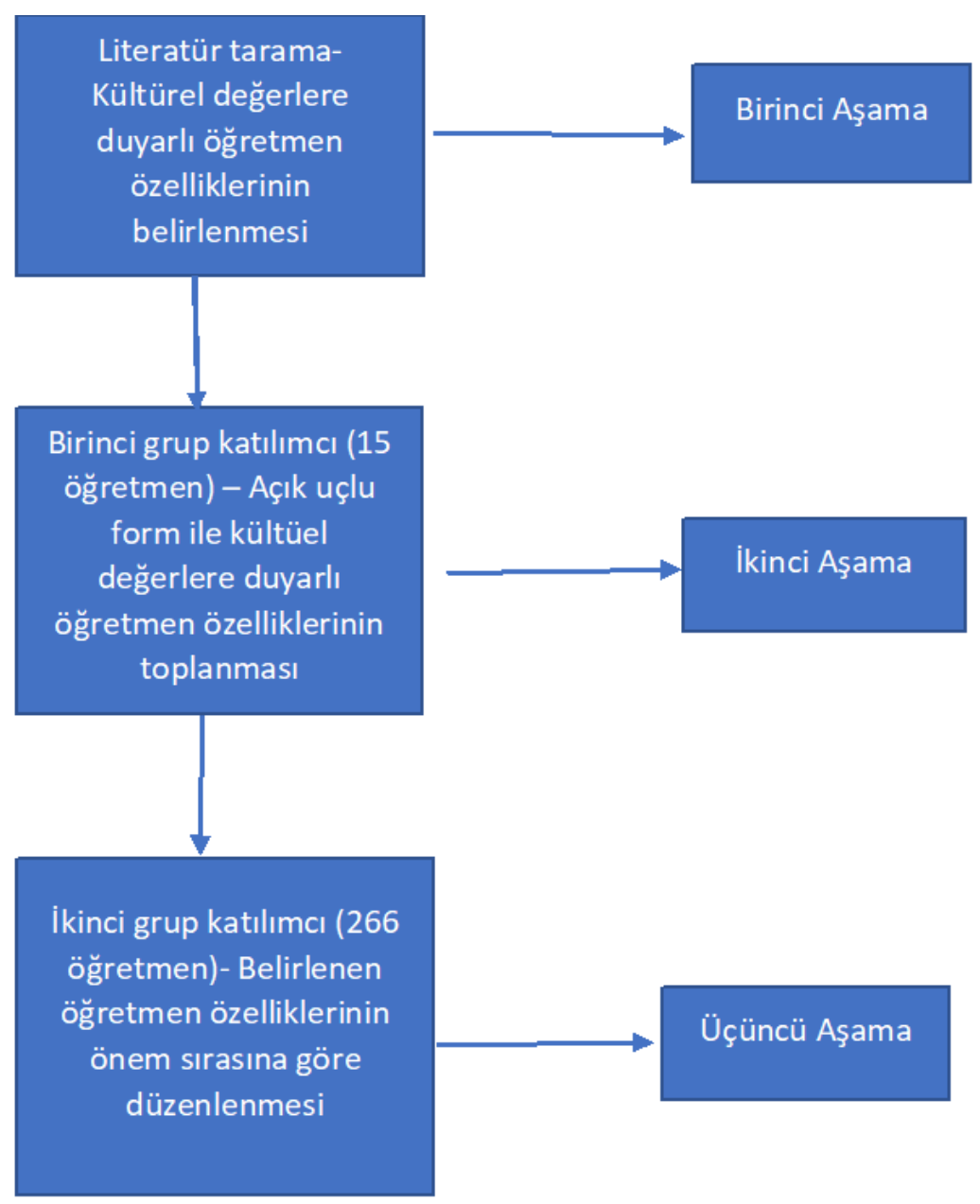

\section{Şekil 1. Araştırmanın Aşamaları}

Şekil 1'de görüldüğü gibi araştırmanın birinci aşamasında ilgili literatür incelenmiş ve kültürel değerlere duyarlı eğitim uygulamaları kapsamında öğretmenlerin sahip olması gereken özellikler ortaya çıkarılmıştır. Araştırmanın ikinci aşamasında öğretmenlerden kültürel değerlere duyarlı öğretmen özelliklerine yönelik görüşler alınmış ve öğretmenlerin görüşlerine göre en fazla belirtilen kültürel değerlere duyarlı öğretmen özellikleri 
belirlenmiştir. Üçüncü aşamada ise öğretmenlerden belirlenen kültürel değerlere duyarlı öğretmen özelliklerinin önem sırasına göre listelenmesi istenmiş ve bu özellikler sıralama yargılarına dayalı ölçekleme yöntemleri ile karşılaştırılmıştır.

\section{Katılımclar}

Araştırmada iki grup katılımcı yer almıştır. Birinci grup katılımcılar 2019 -2020 öğretim yılında devlet okullarında çalışan, okullarında göçmen öğrenci bulunan ya da eğitimde çokkültürlülük dersi alan toplam 15 öğretmenden oluşmuştur. Birinci grup katılımcılar için ölçüt örnekleme kullanılmıştır. Ölçüt örneklemede temel anlayış önceden belirlenmiş bir dizi ölçütü karşılayan durumların çalışılmasıdır. Bu ölçüt önceden belirlenebileceği gibi araştırmacı tarafından da belirlenebilir (Yıldırım ve Şimşek, 2005, 112). Birinci grup katılımcılar için belirlenen ölçüt; okullarında göçmen öğrenci bulunması ya da eğitimde çok kültürlülük dersi almış olması olarak belirlenmiştir. Kültürel değerlere duyarlı öğretmenlerin özelliklerinin belirlenmesi amacıyla hazırlanan açık uçlu form birinci grup katılımcılara uygulanmış ve öğretmenler kültürel değerlere duyarlı öğretmenlerin sahip olması gereken özellikleri belirlemişlerdir. Araştırmanın birinci grup katılımcılarına ilişkin demografik bilgiler Tablo 1.de verilmiştir.

Tablo 1: Birinci Gruba Ait Katılımcı Bilgileri

\begin{tabular}{llll}
\hline Değişkenler & Gruplar & N & Toplam \\
\hline Cinsiyet & Kadın & 8 & 15 \\
\multirow{2}{*}{ Okul Türü } & Erkek & 7 & \\
\cline { 2 - 4 } & İlkokul & 4 & 15 \\
& Ortaokul & 7 & \\
Eğitim Durumu & Lise & 4 & \\
\cline { 2 - 4 } & Lisans & 7 & 15 \\
& Lisansüstü & 2 & \\
\hline
\end{tabular}

Tablo 1'e göre araştırmada birinci grupta görüşlerini belirten 15 katılımcının çeşitli değişkenler bakımından eşit dağılmasına dikkat edilmiştir. Katılımcılar arasında ortaokulda çalışan öğretmenlerin diğer okul türlerine göre sayıca fazlalık gösterdiği ve lisansüstü eğitimini tamamlamış öğretmen sayısının sayıca az olduğu gözlenmektedir. 
Araştırmaya katılan ikinci gruptaki katılımcılar 2019-2020 öğretim yılında devlet okullarında görev yapan 266 öğretmenden oluşmuştur. Bu katılımcılar basit seçkisiz örnekleme yöntemine göre çevrimiçi ortamda oluşturulan form aracılığı ile katılım göstermişlerdir. COVID-19 salgınının başlaması nedeniyle okulların kapalı olması okullardan veri toplanmasının engellemiş ve Denizli ilinin merkez ilçeleri olan Merkezefendi ve Pamukkale ilçelerinde görev yapan öğretmenlere çevrimiçi ortamdan ulaşılmıştır. İkinci grup katılımcılardan belirlenen öğretmen özelliklerini sıralamaları istenmiştir. Araştırmada yer alan ikinci grup katılımcılara ilişkin demografik bilgiler Tablo 2'de verilmiştir.

Tablo 2. Ikinci Gruba Ait Katılımcı Bilgileri

\begin{tabular}{llll}
\hline Değişkenler & Gruplar & $\mathrm{N}$ & Toplam \\
\hline Cinsiyet & Erkek & 129 & 266 \\
& Kadın & 137 & \\
\cline { 2 - 5 } Okul Türü & İlkokul & 61 & 266 \\
& Ortaokul & 114 & \\
Kidem & Lise & 91 & \\
\cline { 2 - 4 } & $0-4$ & 9 & 266 \\
& $5-9$ & 47 & \\
& $10-14$ & 159 & \\
\hline
\end{tabular}

Tablo 2'ye göre belirlenen öğretmen özelliklerini sıralayan 266 öğretmenin \%48,5'i $(n=129)$ erkek, \%51,5'u (n=137) kadın, \%22,9'u (n=61) ilkokulda, \%42,9'u (n=114) ortaokulda, \%34,2'si (n=91) lisede görev yapmakta, \%3,4'ü (n=9) 0-4 y11, \%17,7'si (n=47) 5-9 yı1, \%59,8'i (n=159) 10-14 y1l ve \%19,2’si (n=51) 15-19 y1l k1deme sahiptir.

\section{Verilerin Toplanması}

Araştırmanın verilerini toplamak için birinci aşamada kültürel değerlere duyarlı öğretmen özellikleri, kültürel değerlere duyarlı eğitim kaynaklarından araştırılmış ve bulunan sonuçlara ek olarak ikinci aşamasına öğretmenlere açık uçlu çevrimiçi bir form aracılığg ile en az 5, en fazla 10 kültürel değerlere duyarlı öğretmen özelliği yazmaları istenmiştir. 15 katılımcı öğretmenden gelen 103 özellik incelenerek 10 özellik saptanmıştır. Bu özellikler aşağıda verilmiştir: 
- Öğrencilerin farklı olduğunu düşünme

- Yaşamında demokratik olma

- Öğrencinin geçmiş yaşantısını bilme

- Eğitim öğretim sürecinde sabırlı olma

- Yenilikçi bakış açısına sahip olma

- Mesleki gelişimine önem verme

- Evrensel değerlere sahip olma

- Sevgi dolu yaşam sürme eğiliminde olma

- Herhangi bir bireye ön yargıl1 olmama

- Çevresindeki kişilere karşı anlayışlı olma

Son olarak 266 öğretmenden belirlenen bu 10 özelliği en önemliden daha az önemliye doğru sıralaması istenmiştir. Katılımcılar özellikleri incelemiş ve en önemli gördüğü özelliğe 1 ve daha az önemli gördüğü özelliğe $2,3,4, \ldots 10$ şeklinde numara vererek sıralamışlardır. Çevrimiçi ortamda elde edilen veriler analiz edilmiştir.

\section{Verilerin Analizi}

Araştırmanın birinci ve ikinci aşamasında literatür taraması ve öğretmenlerin görüşleri kapsamında toplanan 103 özellik için frekans kullanılmıştır. Bu kapsamda en fazla tekrar edilen ve ilgili literatür ile bağlantılı 10 özellik alınarak araştırmanın üçüncü aşamasına geçilmiştir. Araştırmanın üçüncü aşamasında elde edilen özelliklerin çevrimiçi ortamda diğer katılımcılar tarafından sıralanması istenmiştir.

Araştırmada elde edilen veriler sıralama yargılarıyla ölçekleme yöntemi ile analiz edilmiştir. $\mathrm{Bu}$ yöntem yargııı kararlarına dayalı ölçekleme yaklaşımındadır. Sıralama yargılarıyla ölçekleme yönteminde araştırmacı uyarıcılar arasındaki en büyük ayrımı yapmaya zorlar. Bu ayrımın yapılması geçerliği yüksek bir ölçek oluşturur ve bu nedenle iç tutarlılık yüksek olur (Turgut ve Baykul, 1992; akt. Bozgeyikli, Toprak, ve Derin, 2016). Araştırma kapsamında da öğretmenlerin sıralama yargılarıyla ölçekleme yapması istenmiştir. Yargıların toplanması için katılımcıların tüm özellikleri düşünmesi ve her bir değeri diğer değerler ile karşılaştırması ve bu karşılaştırmaya numara vermesi istenmiştir. 
Katılımcıların sira numarası vererek doldurdukları formlardan elde edilen veriler $\mathrm{n}\left(\mathrm{S}_{\mathrm{ji}}>\mathrm{S}_{\mathrm{ki}}\right)=\mathrm{f}_{\mathrm{ji}} .\left(\mathrm{f}_{\mathrm{k}}<\mathrm{i}+1 / 2 . \mathrm{f}_{\mathrm{ki}}\right)$ eşitliği yardımı ile $\mathrm{n}\left(\mathrm{S}_{\mathrm{ji}}>\mathrm{S}_{\mathrm{ki}}\right)$ şeklinde (Turgut ve Baykul, 1992; akt. Bozgeyikli, Toprak, ve Derin, 2016) hesaplanarak frekanslar matrisi oluşturulmuştur. Frekanslar matrisinin oluşturulmasında her bir değerin diğer değerden önce kaç kez yazıldığ hesaplanmıştır. Frekans matrisinden yola çıkarak oranlar matrisi bulunmuştur. Oranlar matrisinde elde edilen değerlere karşılık gelen standart değerleri (z) belirlenerek birim normal sapmalar matrisi oluşturulmuştur. Elde edilen bu matristeki her bir sütuna ait elemanlar toplanarak toplam değer bulunmuş ve 10'a bölünerek ölçek değerleri $\left(\mathrm{S}_{\mathrm{j}}\right)$ hesaplanmıştır. Ortalama z değerleri arasından en küçük olan değer eksen başlangıç noktası olan 0'a kaydırılarak ölçek değerleri sıralanmıştır. Bu kaydırma durumlarında en küçük değer negatif ise başlangıç noktasına olan uzaklık kadar ekleme, pozitif ise başlangıç noktasına olan uzaklık kadar çıkarma yapılır. Elde edilen sonuçlar ölçek değerini $\left(S_{c}\right)$ verir. Daha sonra en küçük ölçek değerinden en büyük ölçek değerine kadar sıralanarak analiz tamamlanmış olur.

\section{Bulgular}

Araştırmada sıralama yargılarına dayalı karşılaştırma yöntemi ile kültürel değerlere duyarlı eğitim uygulamalarında öğretmenlerin sahip olması gereken özellikler ölçeklenmiştir. Elde edilen verilerin analizi sonucunda ilk olarak belirlenen bir değerin diğer değerlerden kaç kez önce yazıldığını gösteren frekanslar matrisi oluşturulmuştur. Frekans matrisinde katılımcılara sunulan özellikler A, B, C, ... J şeklinde ifade edilmiştir. Karşılaştırma yolu ile elde edilen bu matriste bir özelliğin diğer özellikten önce kaç defa yazıldığg belirtilmektedir. Oluşturulan frekanslar matrisi Tablo 3.'de verilmiştir.

Tablo 3'e göre belirlenen özelliklerin diğer özelliklerden ikili karşılaştırma yöntemi ile kaç defa önce yazıldığı belirtilmiştir. Örneğin B sütunu ile F satırının kesişiminde bulunan 102 sayısı, B özelliğinin F özelliğinden daha önemli olarak numaralanmasının 102 katılımcı tarafından gerçekleştirildiğini göstermektedir. Matriste köşegen çevresindeki değerler toplam katılımcı sayısını (266) vermektedir. 
Tablo 3. Verilere İlişkin Stralamalarla İlgili Frekanslar Matrisi

\begin{tabular}{lllllllllll}
\hline & A & B & C & D & E & F & G & H & I & J \\
\hline A & 133 & 66 & 43 & 62 & 67 & 100 & 212 & 53 & 91 & 56 \\
B & 200 & 133 & 17 & 177 & 181 & 164 & 161 & 183 & 139 & 176 \\
C & 223 & 249 & 133 & 44 & 29 & 21 & 227 & 37 & 41 & 34 \\
D & 204 & 89 & 222 & 133 & 155 & 136 & 147 & 125 & 140 & 121 \\
E & 199 & 85 & 237 & 111 & 133 & 130 & 188 & 81 & 104 & 79 \\
F & 166 & 102 & 245 & 130 & 136 & 133 & 153 & 142 & 119 & 108 \\
G & 54 & 105 & 39 & 119 & 78 & 113 & 133 & 191 & 192 & 168 \\
H & 213 & 83 & 229 & 141 & 185 & 124 & 75 & 133 & 86 & 49 \\
I & 175 & 127 & 225 & 126 & 162 & 147 & 74 & 180 & 133 & 67 \\
J & 210 & 90 & 232 & 145 & 187 & 158 & 98 & 217 & 199 & 133 \\
\hline
\end{tabular}

Frekans matrisinde her bir hücrede bulunan değer katılımcı sayısına bölünerek oranlar matrisi elde edilmiştir. Elde edilen oranlar matrisi Tablo 4'te verilmiştir.

Tablo 4'e göre frekans matrisinin her bir hücresindeki eleman veri sayısina bölünerek elde edilen oranlar bulunmaktadır. Oranlar matrisinde köşegen etrafındaki değerlerin toplamı 1'e eşittir. Örneğin B özelliğinin A'dan önce yazılma sayısı ile A özelliğinin B'den önce yazılma sayısının toplamı katılımcı sayısına eşittir bu da oranlar matrisinde 1 olarak görülür.

Oranlar matrisinde bulunan her bir hücreye karşılık gelen standart değerler (z) belirlenmiş ve birim normal sapmalar matrisi elde edilmiştir. Elde edilen değerler toplanarak en alt satırda toplam standart değer olarak hesaplanmıştır. Bu değer özellik sayısı olan 10'a bölünerek ortalama değer $S(j)$ bulunmuştur. Ortalama değerlerden en küçük olan başlangıç noktası 0'a alınarak bu değerin 0 ile arasındaki uzaklık diğer değerlere eklenmiştir. Böylece ölçek değerler S(c) elde edilmiştir. Birim normal sapmalar matrisi Tablo 5.'de verilmiştir 
Tablo 4. Verilere İlişkin Stralamalarla İlgili Oranlar Matrisi

\begin{tabular}{lllllllllll}
\hline & $\mathrm{A}$ & $\mathrm{B}$ & $\mathrm{C}$ & $\mathrm{D}$ & $\mathrm{E}$ & $\mathrm{F}$ & $\mathrm{G}$ & $\mathrm{H}$ & $\mathrm{I}$ & $\mathrm{J}$ \\
\hline $\mathrm{A}$ & 0,5 & 0,24812 & 0,161654 & 0,233083 & 0,25188 & 0,37594 & 0,796992 & 0,199248 & 0,342105 & 0,210526 \\
$\mathrm{~B}$ & 0,75188 & 0,5 & 0,06391 & 0,665414 & 0,680451 & 0,616541 & 0,605263 & 0,68797 & 0,522556 & 0,661654 \\
$\mathrm{C}$ & 0,838346 & 0,93609 & 0,5 & 0,165414 & 0,109023 & 0,078947 & 0,853383 & 0,139098 & 0,154135 & 0,12782 \\
D & 0,766917 & 0,334586 & 0,834586 & 0,5 & 0,582707 & 0,511278 & 0,552632 & 0,469925 & 0,526316 & 0,454887 \\
E & 0,74812 & 0,319549 & 0,890977 & 0,417293 & 0,5 & 0,488722 & 0,706767 & 0,304511 & 0,390977 & 0,296992 \\
F & 0,62406 & 0,383459 & 0,921053 & 0,488722 & 0,511278 & 0,5 & 0,575188 & 0,533835 & 0,447368 & 0,406015 \\
G & 0,203008 & 0,394737 & 0,146617 & 0,447368 & 0,293233 & 0,424812 & 0,5 & 0,718045 & 0,721805 & 0,631579 \\
H & 0,800752 & 0,31203 & 0,860902 & 0,530075 & 0,695489 & 0,466165 & 0,281955 & 0,5 & 0,323308 & 0,184211 \\
I & 0,657895 & 0,477444 & 0,845865 & 0,473684 & 0,609023 & 0,552632 & 0,278195 & 0,676692 & 0,5 & 0,25188 \\
J & 0,789474 & 0,338346 & 0,87218 & 0,545113 & 0,703008 & 0,593985 & 0,368421 & 0,815789 & 0,74812 & 0,5 \\
\hline
\end{tabular}


Tablo 5. Verilere İlişkin Stralamalarla İlgili Birim Normal Sapmalar Matrisi

\begin{tabular}{lllllllllll}
\hline & A & B & C & D & E & F & G & H & I & J \\
\hline A & 0 & 0,0987 & 0,0636 & 0,091 & 0,0987 & 0,148 & 0,2881 & 0,0793 & 0,1331 & 0,0832 \\
B & $-0,0987$ & 0 & 0,0239 & 0,2486 & 0,2517 & 0,2324 & 0,2291 & 0,2549 & 0,1985 & 0,2454 \\
C & $-0,0636$ & $-0,0239$ & 0 & 0,0675 & 0,0438 & 0,0319 & 0,3023 & 0,0557 & 0,0596 & 0,0517 \\
D & $-0,091$ & $-0,2486$ & $-0,0675$ & 0 & 0,219 & 0,195 & 0,2088 & 0,1808 & 0,2019 & 0,1736 \\
E & $-0,0987$ & $-0,2517$ & $-0,0438$ & $-0,219$ & 0 & 0,1879 & 0,2611 & 0,1179 & 0,1517 & 0,1179 \\
F & $-0,148$ & $-0,2324$ & $-0,0319$ & $-0,195$ & $-0,1879$ & 0 & 0,219 & 0,2019 & 0,1736 & 0,1591 \\
G & $-0,2881$ & $-0,2291$ & $-0,3023$ & $-0,2088$ & $-0,2611$ & $-0,219$ & 0 & 0,2642 & 0,2642 & 0,2357 \\
H & $-0,0793$ & $-0,2549$ & $-0,0557$ & $-0,1808$ & $-0,1179$ & $-0,2019$ & $-0,2642$ & 0 & 0,1255 & 0,0714 \\
I & $-0,1331$ & $-0,1985$ & $-0,0596$ & $-0,2019$ & $-0,1517$ & $-0,1736$ & $-0,2642$ & $-0,1255$ & 0 & 0,987 \\
J & $-0,0832$ & $-0,2454$ & $-0,0517$ & $-0,1736$ & $-0,1179$ & $-0,1591$ & $-0,2357$ & $-0,714$ & $-0,987$ & 0 \\
\&sütun & $-1,0837$ & $-1,5858$ & $-0,525$ & $-0,772$ & $-0,2233$ & 0,0416 & 0,7443 & 0,3152 & 0,3211 & 2,125 \\
S(j) & $-0,10837$ & $-0,15858$ & $-0,0525$ & $-0,0772$ & $-0,02233$ & 0,00416 & 0,07443 & 0,03152 & 0,03211 & 0,2125 \\
S(c) & 0,05021 & 0 & 0,10608 & 0,08138 & 0,13625 & 0,16274 & 0,23301 & 0,1901 & 0,19069 & 0,37108 \\
\hline
\end{tabular}


Tablo 5'e göre standart değerler köşegen boyunca birbirine göre ters işaretlidir. Bu durum oranların birbirini tamamladığını göstermektedir. Elde edilen değerler sütun boyunca toplanarak toplam standart değer bulunmuştur. Toplam değer 10'a bölünerek ortalama değer elde edilmiş ve bu değerler arasından en küçük değer olan B özelliğine ait $(-0,15858)$ değer başlangıç noktası olan 0'a çekilmiştir. Bu değer negatif olduğu için diğer özelliklere ait değerlere 0,15858 ekleme yapılmıştır.

Elde edilen ölçek değerleri ile ilgili veriler belirlenmiş ve daha net görülebilmesi için grafik üzerinde gösterilmiştir. Veriler üzerinden elde edilen durum Grafik 1.'de verilmiştir.

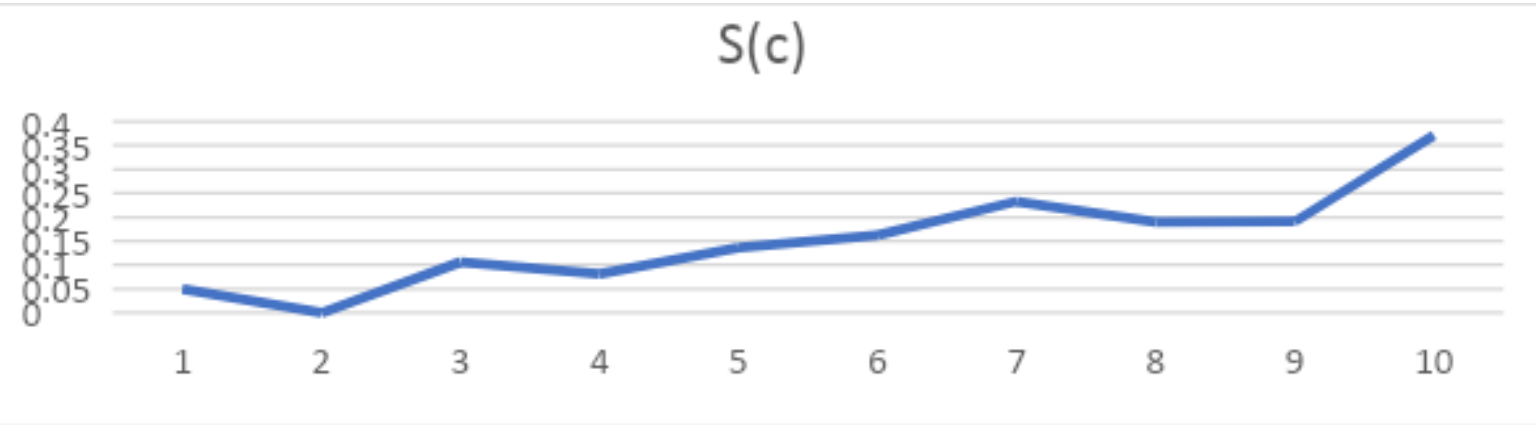

\section{Grafik 1. Katılımcıların Sıralama Yargıları Ölçek Değerleri}

Grafik 1'e göre ölçek değeri en düşük özellik en önemli görülen özellik, ölçek değeri en yüksek olan değer ise diğerlerine göre daha az önemli olarak görülen özellik olarak karşımıza çıkmaktadır. İkinci sırada verilen özellik, diğer özelliklere göre en önemli özellik, onuncu sırada verilen özellik ise diğer özelliklere göre en az öneme sahip özellik olarak karşımıza çıkmaktadır.

Elde edilen bulgular sonucunda ortaya çıkan sıralama aşağıda verilmiştir:

- Yaşamında demokratik olma

- Öğrencilerin farklı olduğunu düşünme

- Eğitim öğretim sürecinde sabırlı olma

- Öğrencinin geçmiş yaşantısını bilme

- Yenilikçi bakış açısına sahip olma 
- Mesleki gelişimine önem verme

- Sevgi dolu yaşam sürme eğiliminde olma

- Herhangi bir bireye ön yargılı olmama

- Evrensel değerlere sahip olma

- Çevresindeki kişilere karşı anlayışlı olma

Elde edilen sıralama doğrultusunda öğretmenlere göre kültürel değerlere duyarlı eğitim uygulamalarında öğretmenlerin sahip olması gereken en önemli özellik "yaşamında demokratik olma" özelliği iken diğerlerine göre en az öneme sahip özellik ise "çevresindeki kişilere karşı anlayışı olma” özelliği olarak ortaya çıkmıştır.

\section{Sonuç, Tartışma ve Öneriler}

$\mathrm{Bu}$ araştırmada kültürel değerlere duyarlı öğretmen özelliklerinin ne olduğu ve bu özelliklerin önem sırası ortaya çıkarılmıştır. Araştırmada ilk sırada ortaya çıkan özellik öğretmenin yaşamında demokratik olmasıdır. Araştırma kapsamında sıralanan özellikler ile kültürel değerlere duyarlı eğitim pedagojisi kapsamındaki özellik sıralaması birbirinden farklı olarak karşımıza çıkmaktadır. Bu durumun çeşitli kültürel nedenleri olabilir. Türkiye, yaşam biçimi olarak farklı sosyoekonomik düzeye sahip olduğundan (Albayrak, 2005) öğretmenler farklı sosyoekonomik düzeyden gelen öğrenciler ile karşı karşıya kalmaktadır. $\mathrm{Bu}$ durum, öğretmenlerin farklılıklardan biri olan sosyoekonomik düzey ile mücadele etmesini gerektirmektedir. Bununla birlikte Türkiye'nin sahip olduğu çokkültürlü yapı da öğretmenlerin farklılıklarla baş etmesini gerekli kılmaktadır. Bu nedenle öğretmenler için en önemli olan özelliğin demokratik olma olarak ortaya çıtığı düşünülebilir. Sınıf içi demokratik bir ortam yaratmak, farklılıklara saygı duyulmasını, öğrencilerin kendilerini rahat hissetmesini, hoşgörülü davranılması sayesinde farklılıklardan kaynaklanan sorunların yok olmasını, öğrencilerin eleştirel düşünmelerini ve iletişimin önyargısız olmasını sağlayabilecektir (Büyükkaragöz ve Kesici, 1996; Demirpolat, 1999; Tahiroğlu ve Aktepe, 2015). Ford da (2007; Akt. Ford ve Kea, 2009) demokratik tutum ve değerlere sahip olmanın kültürel değerlere duyarlı öğretmenler için önemi bir özellik olduğunu belirtmiştir. $\mathrm{Bu}$ farklılıklar sınıfta eşit, eşitlikçi, saygılı ve özgür davranan öğretmen ve öğrenciler sayesinde ayırt edici olmaktan çıkacaktır. Kültürel değerlere duyarlı eğitim için öncelikle bu 
farklılıkların ayrımcılık yaratması engellenmeli ve öğrencinin kendini rahatça ifade etmesi sağlanmalıdır.

İkinci sıradaki öğrencilerin farklı olduğunu düşünme özelliği kültürel değerlere duyarlı eğitim uygulamalarında da yüksek öneme sahip bir özelliktir. Bu noktada ilgili literatür ile uyuşmaktadır (Villegas ve Lucas ,2002; Weinstein, Tomlinson-Clarke ve Curran, 2004; Ford,2007, Akt; Ford ve Kea, 2009). Geçmiş eğitim anlayışından farklı olarak artık öğrencinin boş bir levha olarak okula gelmesinin aksine belirli kalıplarla, inançlarla veya tutumlarla okula geldiği kabul edilmektedir. Bu nedenle her öğrencinin farklı olduğu, bu farklılıkların yönetimi, farklılıklara saygılı olma durumu veya farklılıkları firsata çevirme çabası kültürel değerlere duyarlı eğitim için önemli bir noktadır (Gay, 2000; LadsonBillings, 1999; Pewewardy ve Hammer, 2003; Vonta, 2009). Öğretmenler öğrencilerin farklı olduğunu kabul ederek bu farklılıkların eğitim ortamında ansımalarını dikkate alacak ve eğitim süreçlerini bu kapsamda yöneteceklerdir.

Üçüncü sıradaki özellik eğitim öğretim sürecinde sabırlı olma özelliği aynı zamanda önemli bir öğretmen özelliğidir (Çelikten, Şanal, ve Yeni, 2005). Farklılıkların yaşandığı sınıflarda öğretmenin bu farklılıklara saygılı, evrensel değerler etrafından birleşmiş öğrenciler yetiştirmesi için sabırlı bir şekilde çalışmalarını devam ettirmesi gerekmektedir. Türkiye'de öğretmen özellikleri üzerine yapılan diğer araştırmalarda da sabırlı olma özelliği öğretmenin sahip olması gereken önemli özellikler arasında yer almaktadır (Ay ve Yurdabakan, 2015; Koç, 2010; Saçl1, Bulca, Demirhan, ve Kangalgil, 2009; Erden, 2001). Karakelle'de (2005) yaptığı çalışmada sabırlı olmanın en etkili 10 öğretmen özelliği arasında yer aldığını ortaya çıkarmıştır. Günümüz şartlarında sınıf içinde öğrencilerin farklılıkların daha çok gündeme gelmesi öğretmenlerin daha fazla sorunla uğraşmasına neden olmaktadır. $\mathrm{Bu}$ durumda öğretmenlerin sabırlı olmasının önemini artırmaktadır. Kültürel değerlere duyarlı eğitim kapsamında da öğrencilerin beklentilerini karşılamaya ve akademik anlamda onları desteklemeye çalışan öğretmenlerin sınıf içindeki kültürel farklılıkları yönetme sürecinde daha sabırlı olmasını gerektirmektedir.

Dördüncü sırada ortaya çıkan özellik ilgili literatür ile ters bir şekilde yer almaktadır. Kültürel değerlere duyarlı eğitim kapsamında en önemli özellik olan öğrencinin geçmiş yaşantısını bilme özelliği araştırma kapsamında dördüncü sıradadır. Weinstein, TomlinsonClarke ve Curran'a (2004) göre öğrencilerin geçmişini bilmek kültürel değerlere duyarlı bir sınıf ortamı için öğretmenlerin sahip olması gereken önemli bir özelliktir. Öğretmenin öğrencinin kültürünü tanıması tüm öğrencilerin başarılı olması için önemlidir (Guild, 1994). 
Kültür bireyin düşünme tarzını, davranışını ve iletişim şeklini etkiler (Taylor ve Sobel, 2011). Öğretmenin öğrencinin kültürünü tanıması aynı zamanda öğrencinin düşünme şeklini, iletişim tarzını ve davranışlarını anlaması demektir. Bu durumda kültürel değerlere duyarlı bir eğitim ortamı oluşturmak için oldukça önemlidir. Öğrencinin geçmiş yaşantısının bilinmesi öğrencinin akademik ve sosyal olarak gelişimini destekleyen önemli bir özellik olmasına rağmen araştırmaya katılan öğretmenlerin soruyu dar bir açıdan değerlendirmiş olması bu özelliğin alt sıralara düşmesine neden olmuş olabilir. Bunun yanında kültürel değerlere duyarlı eğitim ile ilgili yeterli bilgi ve deneyim seviyesine sahip olmayan öğretmenler bu özelliğin öneminin farkında olmayabilirler.

Beşinci sırada yer alan yenilikçi bakış açısına sahip olma özelliği "yeni fikirlerin üretilmesi, yaratılması, geliştirilmesi, uygulanması, teşvik edilmesi, fark edilmesi ve tanımlanması" aşamalarını içeren yenilikçi davranış (Thurlings, Evers ve Vermulen, 2015) özelliğinin yansımasıdır. Yenilikçi bakış açısına sahip olma öğrencilerin öğrenme düzeylerini artırmak için gerekli olan (Eaude, 2011) ve değişen topluma uyum sağlamayı kolaylaştıran (Thurlings, Evers ve Vermeulen, 2015) ve öğrencilerin ihtiyaçlarına cevap verebilmeye yardımcı olan (Hargreaves, 1999) bir özelliktir. Okullarda farklı kültürden öğrencilerin bir araya gelmesi yeni bir öğrenme ortamı yaratmış, bu durum öğrencilerin beklenti ve ihtiyaçlarını değiştirmiştir. Tüm öğrencilerin akademik ve sosyal ihtiyaçlarına cevap verebilmek ve onların öğrenme düzeylerini artırmak için geleneksel bakış açısından sıyrılmak ve yenilikçi bir bakış açısına sahip olmak önem taşımaktadır.

Altıncı ve yedinci sırada yer alan mesleki gelişime önem verme ve sevgi dolu yaşam sürme eğiliminde olma özellikleri öğretmenlik mesleğinde öğretmenlerin sahip olması gereken özelliklerdendir. Kültürel değerlere duyarlı eğitim uygulamaları kapsamında düşünüldüğünde öğretmenin sınıfını bir öğrenen topluluk haline getirmesi önemli bir durumdur (Shade, Kelly ve Oberg, 1997). Bunu öğretmen öncelikle kendi mesleki gelişim sürecini yöneterek sağlayacaktır. Öğretmenin çevresi ile iyi iletişim kurması, öğrencilerin sosyalleşmesi sevgi ile ilgili bir durumdur (Ercan, 2014) ve kültürel değerlere duyarlı eğitim uygulamalarında önemli bir noktadır. Bu durumun sağlanabilmesi için öğretmenin çevresine karşı iyimser ve yaşamında da sevgi dolu olması gerekir.

Sekizinci ve dokuzuncu sırada yer alan herhangi bir bireye karşı ön yargılı olmama ile evrensel değerlere sahip olma özellikleri kültürel değerlere duyarlı eğitim kapsamında önemli özellikler arasında yer almaktadır. Buna rağmen araştırma kapsamında alt sıralarda yer almıştır. Bu durum diğer özelliklere sahip bir öğretmenin önyargılara sahip olmayacağı 
ve evrensel değerlere sahip olacağı şeklinde düşünülmüş olabileceği şeklinde yorumlanabilir. Aynı şekilde son sırada yer alan çevresindeki kişilere karşı anlayışlı olma özelliğinin en alt sırada yer almasının nedeni de öğretmenin zaten çevresine karşı anlayışlı olması gerektiği şeklinde yorumlanabilir. Örneğin demokratik davranışlara sahip bir öğretmen farklı görüşlere değer veren, çözüm odaklı, başkalarının refahı için duyarlı, barışçı bir anlayışa sahiptir (Şişman, Güleş, ve Dönmez, 2010). Bu noktada öğretmenler bu özellikleri son sıralara koymuş olabilir. Weinstein, Tomlinson-Clarke ve Curran (2004) ve Ford da (2007; Akt. Ford ve Kea, 2009) öğretmenlerin kültürel değerlere duyarlı olması için öncelikle kendi önyargılarının farkında olması gerektiğini belirtmiştir. Banks’a (1994; Akt. Weinstein, Tomlinson-Clarke ve Curran, 2004) göre de kişiler belirli bir alandaki yaşamın dışına çıkmayarak "kültürel kapsülleme" yaşmakta başka bir deyişle kültürel izolasyon yaşamaktadır. $\mathrm{Bu}$ nedenle önyargıların farkında olunmalı ve bu izolasyon sürecinden kurtulmaya çalışılmalıdır.

Kültürel değerlere duyarlı eğitim uygulamaları farklılıkların olduğu sınıflarda önemli önceliklerden birisidir. Çünkü kültürel değerlere duyarlı eğitim, bilginin oluşum sürecinden başlayıp, öğrencilerin geçmiş yaşamları hakkında bilgi edinme, sosyo kültürel bilinç oluşturma, farklılıklar hakkında olumlu görüşleri destekleme, tüm öğrencilerin öğrenmesini sağlayacak uygun eğitim öğretim yöntemlerini kullanma sürecine kadar devam eden ve tüm öğrencileri kapsamayı öncelik haline getirmiş bir uygulamadır (Villegas ve Lucas, 2002). Bu sürekli tekrar eden süreç düşünüldüğünde öğretmenlerin de kültürel değerlere duyarlı eğitim kapsamında çeşitli özelliklere sahip olması beklenir. Kültürel değerlere duyarlı pedagoji kapsamında değerlendirilen bu özellikler; özenli olmak, empatik olmak, diğer kültürlere yönelik inanç ve tutumlarda yansıtıcı olmak, kültürler hakkında bilgi sahibi olmak, kendi kültürünü yansıtıcı olmak gibi özellikler ortaya çıkmaktadır (Rychly ve Graves, 2012). Bu özellikler yüzeysel bir şekilde belirtilmiş olsa da derinlemesine incelendiğinde çeşitli detaylar ortaya çıkmaktadır.

Kültürel değerlere duyarlı pedagoji çalışmaları, bu noktada öğretmenlerin, öğrencinin geçmiş yaşantısını bilme, öğrencilerin farklılıklarının farkında olma, öğrencilere karşı önyargılı olmama ve sınıf içindeki önyargıların oluşmasına engel olma, yenilikçi ve vizyoner bir bakış açısına sahip olma, öğrenciye ve ailesine karşı anlayışlı olma, evrensel değerler etrafından birleşme, mesleki gelişim sürecini yönetme, demokratik bir ortam oluşturma, akademik olarak yüksek bir beklenti içinde olma ve bu beklentisini sabırla işleme özelliklerine sahip olmaları gerektiğini belirtmektedir (Gay, 2002; Johnson, 2014; Ladson- 
Billings, 2009; Villegas ve Lucas, 2002; Weinstein, Tomlinson-Clarke ve Curran, 2004; Ford, 2007, Akt; Ford ve Kea, 2009). Bu özellikler araştırma kapsamında seçilen özelliklere yakın özelliklerdir.

Türkiye özelindeki öğretmen görüşleri kapsamında incelendiğinde ise kültürel değerlere duyarlı bir öğretmenin; demokratik, öğrencilerinin farklı olduğunu düşünen ve bu farklılıkların önemini bilen, öğrencilerinin akademik ve sosyal yaşantıları ile yüksek beklentilere sahip ve bu beklentisini sabırlı bir şekilde işleyen, öğrencilerinin geçmiş yaşantılarını bilen, yenilikçi bir bakış açısı ile kendini geliştirmeye önem veren ve bu gelişimi mesleki gelişim süreci içinde geliştiren, gerek iş gerekse özel hayatında sevgi dolu bir yaşam sürme eğilimden olan, önyargılarından arınmış, evrensel değerlere sahip ve çevresindeki kişilere karşı anlayışı bir model ortaya çıkmaktadır. Bu özelliklerin bulunduğu öğretmenin, kültürel değerlere duyarlı eğitim uygulamalarını gerçekleştirebileceği düşünülmektedir.

Genel olarak incelendiğinde kültürel değerlere duyarlı öğretmen özellikleri çeşitli ülkelerde kültürel olarak etkilenerek farklılaşabilir. Fakat elde edilen özelliklerin önem sıraları incelenerek gerek eğitim sistemi içerisindeki öğretmenlerin bu özelliklerinin geliştirilmesi veya öğretmen adaylarına bu özelliklerin kazandırılması sağlanabilir. Kültürel değerlere duyarlı eğitim uygulamalarının yaygınlaşmaya başlaması ile bu özelliklerin önemi daha fazla ortaya çıkacaktır. Kültürel değerlere duyarlı öğretmen özelliklerinin geliştirilmesi, eğitim uygulamalarının da okullar da artmasını sağlayacaktır (Ellerbrock, Cruz, Vásquez, ve Howes, 2016; Lucas ve Villegas, 2013; Yuan, 2017). Kültürel değerlere duyarlı eğitimin önemi farklılıkların artması ve bu farklılıkların daha çok bir arada yaşamasıyla birlikte daha belirgin bir hale gelecektir. Öğrencilerin, evrensel değerlere sahip, eleştirel ve yansıtıcı bir bakış açısı ile kendi kültürünü yaşayan kişiler olabilmesi ve toplumun bu şekilde inşası için kültürel değerlere duyarlı eğitim önemli bir noktadır. Araştırmada elde edilen bulgular kapsamında belirlenen özelliklerin öğretmenlerde hizmetiçi eğitim yoluyla, öğretmen adaylarında müfredat aracılığı ile kazandırılması, özelliklerin sıralanmasında bazı özelliklerin ilgili literatüre göre farklı çıkması nedeniyle farklı öğretmenler üzerinde tekrar gerçekleştirilmesi, öğretmenlerin kültürel değerlere duyarlı eğitim uygulamaları noktasında bilinçlendirilmesi önerilmektedir. 
Etik Kurul İzin Bilgisi: Bu araştırma, Pamukkale Üniversitesi Sosyal ve Beşerî Bilimler Araştırma ve Yayın Etiğgi Kurulu 23/09/2020 tarihli 08-2 sayılı kararı ile alınan izinle yürütülmüştür

Yazar Çıkar Çatışması Bilgisi: Herhangi bir çıkar çatışması bulunmamaktadır.

Yazar Katkısı: Birinci yazar, teorik çerçevenin oluşturulması, veri analizi, bulgular, sonuç ve tartışma kısmında katkı sağlamıştır. İkinci yazar, teorik çerçevenin oluşturulması, bulgular, sonuç ve tartışma, öneriler kısmında katkı sağlamıştır.

\section{Kaynakça}

Akbaş, O. (2008). Değer eğitimi akımlarına genel bir bakış. Değerler Ĕgitimi Dergisi, 6(16), 9-27.

Albayrak, A. S. (2005). Türkiye'de illerin sosyoekonomik gelişmişlik düzeylerinin çok değişkenli istatistik yöntemlerle incelenmesi. ZKÜ Sosyal Bilimler Dergisi, 1(1), 153-177.

Ay, Ş., ve Yurdabakan, İ. (2015). Öğretmen adaylarına göre etkili öğretmen özellikleri ve bu özellikler açısından öz-yeterlik algıları. Mehmet Akif Ersoy Üniversitesi Ĕ̆itim Fakültesi Dergisi (33), 148-166.

Banks, J. A. (1994). An introduction to multicultural education. Boston: Allyn ve Bacon.

Banks, C. A. M. ve Banks, J. A. (1995) Equity pedagogy: An essential component of multicultural education, Theory $\quad$ into Practice, 34 (3), 152-158.

Bozgeyikli, H., Toprak, E., ve Derin, S. (2016). Öğretmen adaylarinin mesleki değer algilarinin ölçeklenmesi. Emek ve Toplum, 5(11), 204-225.

Büyükkaragöz, S., ve Kesici, Ş. (1996). Öğretmenlerin hoşgörü ve demokratik tutumları. Ĕ̈itim Yönetimi, 2(3), 353-365.

Çelikten, M., Şanal, M., ve Yeni, Y. (2005). Öğretmenlik mesleği ve özellikleri. Sosyal Bilimler Enstitüsü Dergisi, 19(2), 207-237.

Demirpolat, A. O. (1999). Demokrasi ve demokratik eğitim. Kuram ve Uygulamada Egitim Yönetimi Dergisi, 5(2), 229-248. 
Eaude, T. (2011). Compliance or innovation? Enhanced pro-fessionalism as the route to improving learning and teaching. Education Review, 23(2), 49-57.

Ercan, R. (2014). Öğretmenlerde çocuk sevgisi. Turkish Studies, 9(8), 435-444.

Erden, M. (2001). Öğretmenlik mesleğine giriş. İstanbul: Al $\neg$ kım Yayınları.

Ellerbrock, C. R., Cruz, B. C., Vásquez, A., ve Howes, E. V. (2016). Preparing culturally responsive teachers: Effective practices in teacher education. Action in Teacher Education, 38(3), 226-239.

Ford, D. Y., ve Kea, C. D. (2009). Creating culturally responsive instruction: For students' and teachers' sake. Focus on Exceptional Children.41(9), 1-17.

Ford, D. Y. (2010). Culturally Responsive Classrooms: Affirming Culturally Different Gifted Students, Multicultural Issues, 33(1), 50-53.

Gay, G. (2000). Culturally responsive teaching. New York: Teachers College Press.

Gay, G. (2002). Preparing for culturally responsive teaching. Journal of Teacher Education, 53(2), 106-116.

Gay, G. (2018). Culturally responsive teaching: Theory, research, and practice. (3rd Ed.). Teachers College Press

Guild, P. (1994). The culture/Learning style connection, Educational Ladership, 51(8), 1621.

Hargreaves, D. (1999). Schools and the future: The key role of innovation in innovating schools. In Innovationg Schools (s. 45-57). Paris: OECD PublicationsEnvironment, Prentice Hall International Inc., London.

Jarosinski, T. (2018). Culturally responsive teaching practices for educators of culturally and linguistically diverse students. Education and Human Development, Master's Theses. 1107. The College at Brockport: State University of New York https://digitalcommons.brockport.edu/ehd_theses/1107

Johnson, L. (2014). Culturally responsive leadership for community Empowerment. Multicultural Education Review, 6(2), 145-170. doi: https://doi.org/10.1080/2005615X.2014.11102915

Karakelle, S. (2005). Öğretmenlerin etkili öğretmen tanımlarının etkili öğretmenlik boyutlarına göre incelenmesi, Eğitim ve Bilim, 30(135), 1-10. 
Karasar, N. (2000). Bilimsel araştırma yöntemi (10. Bask1 b.). Ankara: Nobel Yayın Dağıtım.

Karataş, K. (2020). Kültürel değerlere duyarlı öğretmen ölçeği geçerlik ve güvenirlik çalışması, Elektronik Sosyal Bilimler Dergisi, 19(76), 1761 - 1775.

Karataş, K., ve Oral, B. (2017). Kültürel değerlere duyarlı eğitime hazırbulunuşluk ölçeği. Eğitim Bilimleri Araştırmaları Dergisi, 7(2), 257-268.

Koç, A. (2010). Din kültürü ve ahlâk bilgisi öğretmenlerinin yeterlikleri. Değerler Eğitimi Dergisi, 8(19), 107-149.

Kotluk, N., ve Kocakaya, S. (2018a). Türkiye için alternatif bir anlayış: Kültürel değerlere duyarlı eğitim. YYÜ Eğitim Fakültesi Dergisi, 15(1), 749-789.

Kotluk, N. ve Kocakaya,S. (2018b). Culturally relevant/responsive education: What do teachers think in Turkey, Journal of Ethnic and Cultural Studies, 5(2), 98-117.

Kotluk, N. ve Kocakaya, S. (2017). Teachers' culturally relevant teaching self-efficacy beliefs in Turkey: A scale development study. 2nd Eurasian Conference on Language and Social Sciences (ECLSS 2017), 29 September -October 1, 2017, Antalya, Turkey.

Ladson-Billings, G. (2009). The dream keepers: Successful teachers of African American children. San Francisco: Wiley.

Ladson-Billings. G. (1999). Preparing teachers for diverse student populations: A critical race theory perspective, Review of Research in Education, 24(1), 211-247.

Lazar, A. M., Edwards, P. A. ve McMillon, G. T. (2012). Bridging literacy and equity: the essential guide to social equity teaching. New York, NY: Teachers College Press

Lucas, T., ve Villegas, A. M. (2013). Preparing linguistically responsive teachers: Laying the foundation in preservice teacher education. Theory into Practice, 52(2), 98-109.

MEB. (1973). Milli Eğitim Temel Kanunu. Resmi Gazete, 24.6.1973, Say1, 14574. June 14, 2020 MEB Mevzuat: https://www.mevzuat.gov.tr/MevzuatMetin/1.5.1739.pdf

Nayir, F. (2019). Kültürel değerlere duyarlı öğretmen rolleri ölçeğinin geliştirilmesi, Turkish Studies Educational Sciences, 14(I6), 3273-3292.

Nieto, S. (2002). Language, culture, and teaching: Critical perspectives for a new century. Mahway, NJ: Lawrence Erlbaum. 
Pewewardy, C., ve Hammer, P. C. (2003). Culturally responsive teaching for American Indian students. ERIC Digest, 1-9.

Rychly, L., ve Graves, E. (2012). Teacher characteristics for culturally responsive pedagogy. Multicultural Perspectives, 14(1), 44-49. doi: https://doi.org/10.1080/15210960.2012.646853

Saçl1, F., Bulca, Y., Demirhan, G., ve Kangalgil, M. (2009). Beden eğitimi öğretmenlerinin kişisel nitelikleri. Spor Bilimleri Dergisi, 20(4), 145-151.

Shade, B. J., Kelly, C., ve Oberg, M. (1997). Creating culturally responsive classrooms. Washington DC: American Psychological Association.

Şahin, A. (2011). Öğretmen algılarına göre etkili öğretmen davranışları. Ahi Evran Üniversitesi Ĕ̌itim Fakültesi Dergisi, 12(1), ss.239-259.

Şişman, M., Güleş, H., ve Dönmez, A. (2010). Demokratik bir okul kültürü için yeterlilikler çerçevesi. Uşak Üniversitesi Sosyal Bilimler Dergisi, 3(1), 167-182.

Tahiroğlu, M., ve Aktepe, V. (2015). Değerler eğitimi yaklaşımlarına göre geliştirilen etkinliklerin demokratik algı ve davranışlar üzerine etkisi. Değerler Ĕ̆itimi Dergisi, 12(30), 309-345.

Taylor, S.V. ve Sobel, D.M. (2011). Culturally responsive pedagogy: Teaching like our stuents' lives matter, Howard Hause: Emerald Group Publishing Limited.

Thurlings, M., Evers, A. T., ve Vermeulen, M. (2015). Toward a model of explaining teachers' innovative behavior: a literature review. Review of Educational Research, 85(3), 430-471. doi: 10.3102/00346543145579

Turgut, M. F., ve Baykul, Y. (1992). Ölçekleme teknikleri. Ankara: ÖSYM Yayınları.

UNHCR. (2019, July). UNHCR BM Mülteci örgütü. December 6, 2019 UNHCR Türkiye İstatistikleri: https://www.unhcr.org/tr/unhcr-turkiye-istatistikleri

Villegas, A. M. ve Lucas, T. (2002). Preparing culturally responsive teachers. Journal of Teacher Education, 53(1), 20-32. doi:10.1177/0022487102053001003.

Villegas, A. M., ve Lucas, T. (2007). The culturally responsive teacher. Educational Leadership, 64(6), 28-33.

Weinstein C., Tomlinson-Clarke S., ve Curran M. (2004). Toward a conception of culturally responsive classroom management. Journal of Teacher Education, 55(1), 25-38. 
G, Sarıdaş, ve F, Nayir / Pamukkale Üniversitesi Eğitim Fakültesi Dergisi, 53, 355-377, 2021

Weinstein, C., Curran, M., and Tomlinson-Clarke, S. (2003). Culturally responsive classroom management: awareness into action. Theory into Practice, 42(4), 269-276.

Vonta, T. (2009). Building teacher's capacity for quality education - Condition for inclusiveness. Inter Network Conference (s. 156-167). Spain: LJUBLJANA Conference Proceedings.

Yuan, H. (2017). Developing culturally responsive teachers: Current issues and a proposal for change in teacher education programs. World Journal of Education, 7(5), 66-78.

Yıldırım, A., ve Şimşek, H. (2013). Sosyal bilimlerde nitel araştırma yöntemleri. Seçkin Yayınc1lık. 


\title{
Scaling Culturally Responsive Teacher Characteristics with Ranking Judgments
}

\author{
Gürkan SARIDAŞ* $\quad$ Funda NAYIR ${ }^{* *}$
}

- Received: 17.11.2020 • Accepted: 23.04.2021 • Online First: 23.04.2021

\begin{abstract}
The emergence of an understanding of culturally responsive teaching has established new roles for teachers, and it has become important for teachers to take a role that integrates cultural differences in the teaching environment by stepping out of traditional roles. It is thought that it is important to reveal the characteristics of culturally responsive teachers and their importance in the teaching process. The research aimed to identify the characteristics of teachers within the framework of practices culturally responsive teaching. The research consists of three phases. In the first and second stages, teacher characteristics were investigated within the framework of culturally responsive teaching practices, and in the third stage, these characteristics were compared with scaling methods based on ranking judgments. Data from the study was collected from 266 teachers who served in public schools during the 2019-2020 school year. Data obtained in the study was analyzed by the scaling method with sorting judgments. As a result of the findings, being democratic in the life of culturally responsive teachers, thinking that students are different, being patient in the education and training process, knowing the student's past life, having an innovative perspective, giving importance to professional development, tending to live a loving life, it has been seen that they are listed as not being prejudiced, having universal values and being understanding towards the people around them. It has been proposed that the characteristics determined within the scope of the results obtained in the study should be acquired by teachers through in-service training, by the curriculum in teacher candidates and that teachers should be aware of practices culturally responsive teaching.
\end{abstract}

Keywords: culturally responsive teacher, being democratic, recognizing student's culture, scaling based on ranking judgments.

\section{Cited:}

Sarıdaş, G., \& Nayir, F. (2021).Scaling culturally responsive teacher characteristics with ranking judgments. Pamukkale University Journal of Education, 53,355377.doi:10.9779.pauefd.827009

\footnotetext{
* Ministry of National Education, theapeiron@gmail.com, ORCID : 0000-0002-7989-2130

** Pamukkale University, fnayir09@gmail.com, ORCID : 0000-0002-9313-4942
} 


\section{Introduction}

Today, with the increasing coexistence of different cultures, needs and expectations in education have started to change. Accordingly, teachers must be sensitive to cultural differences in the education and training process and pay attention to these differences. Teaching is a profession that contains values in itself. These values form the codes of the teaching profession; in other words, they determine the characteristics that teachers should have. It is thought that it is important to reveal the characteristics of culturally responsive teachers and the importance of these features in the education and training process.

Teachers focus on improving the characteristics of people in the community and giving them a variety of characteristics. Because these characteristics determine the standard of living, people in society know critical situations and what direction they should use their preferences. The aim of developing these characteristics is to regulate the individual's life and education in society and increase the efficiency that they will contribute to society (Akbas, 2008; Celikten, Sanal, \& Yeni, 2005). General purposes contained in the Basic Law of National Education (MEB, 1973) (Article 2) when examined, Kemalist, patriotic, healthy, connected to the nation, Democratic, scientific thinkers, know their duties and responsibilities, such as the characteristics that should be gained to people in society are encountered. These characteristics are conveyed by teachers to students in a wide range, while in a narrower sense, teachers also have a variety of characteristics. The characteristics that teachers should have been examined by the Ministry of Education in two groups, personally and professionally. When these properties are examined; Characteristics such as being open-minded, taking student expectations into account, attaching importance to differences, being an innovative, researcher, collaborative, patient, having field and professional knowledge, being able to organize the teaching environment appropriately, and having a general culture (Celikten, Sanal, \& Yeni, 2005; Sahin, 2011) come into being. It is possible to say that the characteristics of the teacher emerge as being democratic, giving importance to individual differences, depending on their profession, and giving importance to professional development.

Within the scope of the research, the characteristics of teachers for educational practices culturally responsive were focused. Culturally responsive education can be defined as creating channels for students to learn more effectively by using culturally diverse students' cultural characteristics, experiences, and perspectives (Gay, 2002). As can be understood from the definition, the focus of educational practices is cultural values as a tool. 
At this point, teachers who will perform educational practices culturally responsive should have various characteristics. These qualities are to be culturally literate to update teaching methods and techniques constantly, to ensure that the class participates in the lesson with high self-confidence, to ensure that everyone in the classroom is respectful of differences, to carry out teacher-based curriculum development studies, to develop students' critical thinking skills, to gather around universal values (Pewewardy \& Hammer, 2003).

Only a culturally responsive approach by rejecting the authority teachers' teachers facilitate the learning process and adopts an approach that guides students (Gay, 2002a; Ladson-Billings, 2009; Banks \& Banks, 1995). These teachers create a common culture in the classroom by revealing students' potential, and they pay attention to understanding, democracy, and impartiality (Ladson-Billings, 1999). Culturally responsive teachers emphasize group work and collaborative learning (Villegas and Lucas, 2002; Nieto, 2002) strive for their academic development by keeping high expectations of students (Villegas and Lucas, 2002). These teachers communicate with their families to contribute to students 'learning (Jarosinski, 2018; Lazar, Edwards, \& McMillon, 2012) and include students' cultural differences in the teaching process (Gay, 2018). Simultaneously, culturally responsive teachers are aware of their cultural backgrounds and students' cultural backgrounds (Weinstein, Curran \& Tomlinson-Clarke, 2003; Weinstein, Tomlinson-Clarke $\&$ Curran, 2004). As can be seen, culturally responsive teachers see cultural differences as contributing to the teaching process, value each student, and respect each student's cultural knowledge (Nayir, 2019). In this context, the teacher must do research that supports academic and social development free from prejudices by questioning his own culture in a way that is aware of his own culture. A culturally responsive teacher can be defined as a teacher who has different roles and responsibilities, knows the background of students, and sees the differences that students have as wealth, organizes the educational environment from a critical point of view, and allows all their students to benefit from this environment on an equal level. Therefore, it is important to determine certain characteristics and the importance of these characteristics to fully identify the culturally responsive teacher.

Culturally responsive teaching is a concept that began to be investigated in recent years in Turkey. However, according to UNHCR (2019) data in Turkey, 3.6 million Syrian, 170 thousand Afghanistan, 142 thousand Iraq, 39 thousand Iran, 5 thousand 7 hundred Somalia, and 11 thousand 7 hundred other country citizens are immigrants. Cultural differences are beginning to be observed more in Turkey with the increase in migrations, so 
it can be said that there is a greater need for culturally responsive educational practices. At this point, it is necessary to determine the characteristics of teachers who will carry out educational practices as culturally responsive. Teacher training and culturally responsive in studies about practices in Turkey; It is seen that readiness regarding education culturally responsive (Karatas \& Oral, 2017), understanding of culturally responsive teaching (Kotluk \& Kocakaya, 2018a), opinions of teachers on culturally responsive teaching (Kotluk \& Kocakaya, 2018b; Kotluk \& Kocakaya, 2017) and roles of culturally responsive teachers (Nayir, 2019) and culturally responsive teachers (Karatas, 2020) are mentioned. In these studies, Nayir (2019) and Karatas (2020) tried to reveal the roles of teachers sensitive to cultural values and the situations in which these teachers have sensitivity to cultural values. However, the most important characteristics that a teacher sensitive to cultural values should not have been studied. The research will contribute to the relevant literature, as it will provide information on what skills teachers should develop through in-service training to be conducted by the Ministry of National Education (MEB), and on what skills teacher candidates should develop in pre-service education by the Council of Higher Education (YÖK). When the relevant literature is examined, it is observed that there is no clarity in determining the characteristics of culturally responsive teachers. Thus, the results obtained within the scope of the research will contribute to the literature and reveal the values that teachers and teacher candidates must earn. This research aimed to identify the characteristics of teachers within the framework of culturally responsive educational practices. For this purpose, the following sub-objectives have been determined:

- What are the characteristics of teachers within the scope of culturally responsive teaching practices?

- What is the order of importance of these features within the scope of culturally responsive teaching practices?

\section{Method}

\section{Research Models}

The research is a quantitative study in the general survey model. Survey models include research conducted over the entire universe or a group taken from it to make a general judgment about the universe (Karasar, 2000). In this study, it can be said that there is research in the screening pattern since it is tried to determine how the characteristics of 
culturally responsive teachers have a ranking based on the views of the teacher. The research was carried out in three stages. The three stages of the research are given in Figure 1.

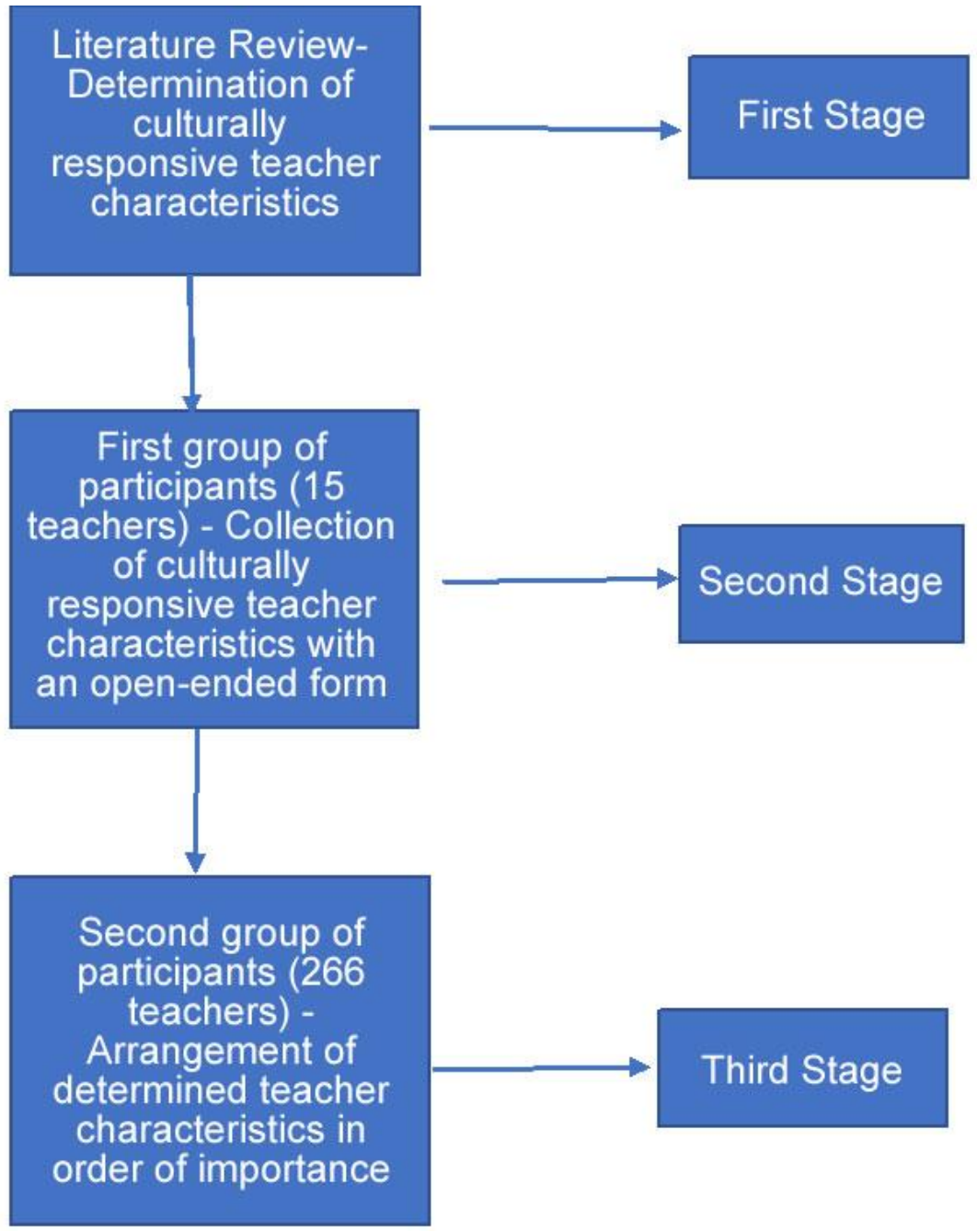

Figure1. Stages of Research

As shown in Figure 1, at the first stage of the research, the relevant literature was examined, and the characteristics that teachers should have within the framework of culturally responsive teaching practices were revealed. In the second stage of the study, opinions of culturally responsive teachers were taken from the teachers. According to the teachers' opinions, the characteristics of the culturally responsive teachers the most stated cultural values were determined. In the third stage, teachers were asked to list the culturally responsive teacher characteristics in order of importance, and these features were compared with scaling methods based on ranking judgments. 


\section{Participants}

Two groups of participants took part in the study. The first group consisted of 15 teachers working in public schools, having immigrant students in their schools, or taking multiculturalism in education in the 2019-2020 academic years. Criteria sampling was used for the first group of participants. The basic understanding of criteria sampling is the study of situations that meet a predetermined set of criteria. The researcher can determine this criterion in advance (Lightning \& Lightning, 2005, 112). The criteria set for the first group of participants were determined as having immigrant students in their schools or having taken a multiculturalism course in education. An open-ended form was applied to the first group of participants to determine the characteristics of teachers who are sensitive to culture, and teachers identified the characteristics that culturally responsive teachers should have. The demographic information of the first group participants of the study is given in Table 1 .

Table 1: Demographic Information of the First Group

\begin{tabular}{llll}
\hline Variables & Groups & N & Total \\
\hline Gender & Female & 8 & 15 \\
\multirow{3}{*}{ School Type } & Male & 7 & \\
\cline { 2 - 4 } & Primary School & 4 & 15 \\
\multirow{3}{*}{ Education Status } & Secondary School & 7 & \\
& High School & 4 & \\
\cline { 2 - 4 } & Graduate & 7 & 15 \\
& Postgraduate & 2 & \\
\hline
\end{tabular}

According to Table 1, attention was paid to the equal distribution of 15 participants who expressed their views in the first group regarding various variables. Among the participants, it is observed that teachers working in secondary schools outnumber other types of schools, and the number of teachers who have completed postgraduate studies is small.

Participants in the second group participating in the study consisted of 266 teachers working in public schools in the 2019-2020 school years. These participants participated through a form created online according to a simple non-selective sampling method. Due to the beginning of the covid-19 epidemic, the closure of schools prevented the collection of data from schools and teachers working in the Central Districts of Denizli province, Merkezefendi and Pamukkale were reached online. The second group of participants was 
asked to rank the teacher characteristics determined. Demographic information about the second group of participants in the study is given in Table 2.

Table 2. Demographic Information of the Second Group

\begin{tabular}{lllc}
\hline Variables & Groups & N & Total \\
\hline Gender & Male & 129 & 266 \\
School Type & Female & 137 & \\
\cline { 2 - 4 } & Primary School & 61 & 266 \\
& Secondary School & 114 & \\
Seniority & High School & 91 & \\
\cline { 2 - 4 } & $0-4$ & 9 & 266 \\
& $5-9$ & 47 & \\
& $10-14$ & 159 & \\
\hline
\end{tabular}

According to Table 2, out of 266 teachers who listed the determined teacher characteristics; $48.5 \%(\mathrm{n}=129)$ were male, $51.5 \%(\mathrm{n}=137)$ were female, $22.9 \%(\mathrm{n}=61)$ were in primary school, $42.9 \%(\mathrm{n}=114) 34.2 \%(\mathrm{n}=91)$ work in secondary school, $3.4 \%(\mathrm{n}$ = 9) 0-4 years, $17.7 \%(\mathrm{n}=47) 5-9$ years, \% $59.8(\mathrm{n}=159)$ of them had 10-14 years of seniority and $19.2 \%(n=51)$ of them had a seniority of $15-19$ years.

\section{Data Collection}

In order to collect the data of the study, in the first stage, the characteristics of culturally responsive teachers were investigated from culturally responsive educational resources. In the second stage, teachers were asked to write at least 5, at most ten cultural values sensitive teacher characteristics through an open-ended online form. By examining 103 characteristics from 15 participating teachers, ten characteristics were determined. These features are given below:

- Thinking that students are different

- Being democratic in life

- Knowledge of the student's past life

- Being patient in the education and training process 
- Having an innovative perspective

- Giving importance to professional development

- Having universal values

- Tendency to lead a loving life

- Not being biased towards an individual

- Be understanding towards those around you

Finally, 266 teachers were asked to rank these ten characteristics from the most important to the less important. Participants examined the characteristics and listed them by giving numbers in the form of 1 for the feature they considered most important and 2, 3, $4 \ldots$ 10 for the feature they considered less important. Data obtained online has been analyzed.

\section{Data Analysis}

In the first and second stages of the research, the frequency was used for 103 features collected within the scope of the literature review and teachers ' opinions. In this context, the third phase of the research was started by taking the ten most repeated characteristics and related them to the relevant literature. In the third stage of the study, the characteristics obtained were asked to be sorted online by other participants.

The data obtained in the study were analyzed by the scaling method with sequencing judgments. This method is a scaling approach based on judge decisions. In the scaling method with sequencing judgments, the researcher forces the researcher to make the biggest distinction between stimuli. Making this distinction creates a scale with high validity, and therefore, internal consistency is high (Turgut \& Baykul, 1992; cited in Bozgeyikli, Toprak, \& Derin, 2016). As part of the research, teachers were also asked to scale with ranking judgments. In order to collect judgments, participants were asked to consider all characteristics and compare each value with other values and give numbers to this comparison. The data was obtained from the forms filled out by the participants by giving the sequence number $n(\mathrm{Sji}>\mathrm{Ski})=$ fji. $(\mathrm{Fk}<\mathrm{i}+1 / 2$ fki) in the form of $\mathrm{n}(\mathrm{Sji}>\mathrm{Ski})$ (Turgut \& Baykul, 1992; cited in Bozgeyikli, Toprak, \& Derin, 2016) were calculated, and the frequencies matrix was formed. Creating the frequency's Matrix was calculated how many times each value was written before the other value. Based on the frequency matrix, the 
ratios matrix has been found. The standard values $(\mathrm{z})$ corresponding to the values obtained in the ratio's Matrix were determined, and the unit normal deviations matrix was formed. The total value was found by summing the elements belonging to each column in this Matrix, and the scale values $(\mathrm{Sj})$ were calculated by dividing by 10 . Scale values are listed by shifting the value, which is the smallest value among the average $\mathrm{z}$ values, to 0 , the axis starting point. If the minimum value is negative, the distance to the starting point is added, and if it is positive, the distance to the starting point is subtracted. The resulting results give the scale value $(\mathrm{Sc})$. The analysis is then completed by sorting from the smallest scale value to the largest scale value.

\section{Findings}

The comparison method based on ranking judgments scaled the characteristics teachers should have in culturally responsive educational practices in the study. As a result of the data analysis, a matrix of frequencies was created that shows how many times a value determined was written before other values. The features presented to the participants in the frequency matrix are expressed as A, B, C... J. This Matrix obtained by comparison shows how many times a feature is written before another feature. The created frequencies matrix is given in Table 3 .

Table 3. Matrix of Frequencies Related to Data Rankings

\begin{tabular}{lllllllllll}
\hline & A & B & C & D & E & F & G & H & I & J \\
\hline A & 133 & 66 & 43 & 62 & 67 & 100 & 212 & 53 & 91 & 56 \\
B & 200 & 133 & 17 & 177 & 181 & 164 & 161 & 183 & 139 & 176 \\
C & 223 & 249 & 133 & 44 & 29 & 21 & 227 & 37 & 41 & 34 \\
D & 204 & 89 & 222 & 133 & 155 & 136 & 147 & 125 & 140 & 121 \\
E & 199 & 85 & 237 & 111 & 133 & 130 & 188 & 81 & 104 & 79 \\
F & 166 & 102 & 245 & 130 & 136 & 133 & 153 & 142 & 119 & 108 \\
G & 54 & 105 & 39 & 119 & 78 & 113 & 133 & 191 & 192 & 168 \\
H & 213 & 83 & 229 & 141 & 185 & 124 & 75 & 133 & 86 & 49 \\
I & 175 & 127 & 225 & 126 & 162 & 147 & 74 & 180 & 133 & 67 \\
J & 210 & 90 & 232 & 145 & 187 & 158 & 98 & 217 & 199 & 133 \\
\hline
\end{tabular}

According to Table 3, it is indicated how many times the properties determined were written before the other properties by binary comparison method. For example, the number 102 at the intersection of Column B and Row F indicates that 102 participants perform the 
numbering of property B as more important than property F. The values around the diagonal in the Matrix give the total number of participants (266).

In the frequency matrix, the value contained in each cell is divided by the number of participants, resulting in a ratio Matrix. The resulting ratios matrix is given in Table 4. 
Table 4. Ratios Matrix Related to Data Rankings

\begin{tabular}{llllllllllll}
\hline & A & B & C & D & E & F & G & H & I & J \\
\hline A & 0,5 & 0,24812 & 0,161654 & 0,233083 & 0,25188 & 0,37594 & 0,796992 & 0,199248 & 0,342105 & 0,210526 \\
B & 0,75188 & 0,5 & 0,06391 & 0,665414 & 0,680451 & 0,616541 & 0,605263 & 0,68797 & 0,522556 & 0,661654 \\
C & 0,838346 & 0,93609 & 0,5 & 0,165414 & 0,109023 & 0,078947 & 0,853383 & 0,139098 & 0,154135 & 0,12782 \\
D & 0,766917 & 0,334586 & 0,834586 & 0,5 & 0,582707 & 0,511278 & 0,552632 & 0,469925 & 0,526316 & 0,454887 \\
E & 0,74812 & 0,319549 & 0,890977 & 0,417293 & 0,5 & 0,488722 & 0,706767 & 0,304511 & 0,390977 & 0,296992 \\
F & 0,62406 & 0,383459 & 0,921053 & 0,488722 & 0,511278 & 0,5 & 0,575188 & 0,533835 & 0,447368 & 0,406015 \\
G & 0,203008 & 0,394737 & 0,146617 & 0,447368 & 0,293233 & 0,424812 & 0,5 & 0,718045 & 0,721805 & 0,631579 \\
H & 0,800752 & 0,31203 & 0,860902 & 0,530075 & 0,695489 & 0,466165 & 0,281955 & 0,5 & 0,323308 & 0,184211 \\
I & 0,657895 & 0,477444 & 0,845865 & 0,473684 & 0,609023 & 0,552632 & 0,278195 & 0,676692 & 0,5 & 0,25188 \\
J & 0,789474 & 0,338346 & 0,87218 & 0,545113 & 0,703008 & 0,593985 & 0,368421 & 0,815789 & 0,74812 & 0,5 \\
\hline
\end{tabular}


According to Table 4, there are ratios obtained by dividing the number of element data in each cell of the frequency matrix. In the ratio's Matrix, the sum of the values around the diagonal is equal to 1 . For example, the sum of the number of written features of $B$ before $\mathrm{A}$ and the number of times that feature $\mathrm{A}$ before $\mathrm{B}$ is equal to the number of participants, seen as 1 in the Matrix ratio.

The standard values (z) corresponding to each cell in Matrix's ratios were determined, and the unit normal deviations Matrix was obtained. The resulting values are collected and calculated as the total standard value in the bottom line. This value was divided by 10 , which is the number of properties, and the average value $S(j)$ was found. The starting point, which is the smallest of the average values, was taken to 0 , and the distance between this value and 0 was added to the other values. Thus, the scale values $\mathrm{S}(\mathrm{C})$ was obtained. Unit normal deviations matrix is given in Table 5. 
Table 5. Unit Normal Deviations Matrix Related to Data Rankings

\begin{tabular}{lllllllllll}
\hline & $\mathrm{A}$ & $\mathrm{B}$ & $\mathrm{C}$ & $\mathrm{D}$ & $\mathrm{E}$ & $\mathrm{F}$ & $\mathrm{G}$ & $\mathrm{H}$ & $\mathrm{I}$ & $\mathrm{J}$ \\
\hline $\mathrm{A}$ & 0 & 0,0987 & 0,0636 & 0,091 & 0,0987 & 0,148 & 0,2881 & 0,0793 & 0,1331 & 0,0832 \\
$\mathrm{~B}$ & $-0,0987$ & 0 & 0,0239 & 0,2486 & 0,2517 & 0,2324 & 0,2291 & 0,2549 & 0,1985 & 0,2454 \\
$\mathrm{C}$ & $-0,0636$ & $-0,0239$ & 0 & 0,0675 & 0,0438 & 0,0319 & 0,3023 & 0,0557 & 0,0596 & 0,0517 \\
$\mathrm{D}$ & $-0,091$ & $-0,2486$ & $-0,0675$ & 0 & 0,219 & 0,195 & 0,2088 & 0,1808 & 0,2019 & 0,1736 \\
$\mathrm{E}$ & $-0,0987$ & $-0,2517$ & $-0,0438$ & $-0,219$ & 0 & 0,1879 & 0,2611 & 0,1179 & 0,1517 & 0,1179 \\
$\mathrm{~F}$ & $-0,148$ & $-0,2324$ & $-0,0319$ & $-0,195$ & $-0,1879$ & 0 & 0,219 & 0,2019 & 0,1736 & 0,1591 \\
$\mathrm{G}$ & $-0,2881$ & $-0,2291$ & $-0,3023$ & $-0,2088$ & $-0,2611$ & $-0,219$ & 0 & 0,2642 & 0,2642 & 0,2357 \\
$\mathrm{H}$ & $-0,0793$ & $-0,2549$ & $-0,0557$ & $-0,1808$ & $-0,1179$ & $-0,2019$ & $-0,2642$ & 0 & 0,1255 & 0,0714 \\
$\mathrm{I}$ & $-0,1331$ & $-0,1985$ & $-0,0596$ & $-0,2019$ & $-0,1517$ & $-0,1736$ & $-0,2642$ & $-0,1255$ & 0 & 0,987 \\
$\mathrm{~J}$ & $-0,0832$ & $-0,2454$ & $-0,0517$ & $-0,1736$ & $-0,1179$ & $-0,1591$ & $-0,2357$ & $-0,714$ & $-0,987$ & 0 \\
$\sum$ column & $-1,0837$ & $-1,5858$ & $-0,525$ & $-0,772$ & $-0,2233$ & 0,0416 & 0,7443 & 0,3152 & 0,3211 & 2,125 \\
$\mathrm{~S}(\mathrm{j})$ & $-0,10837$ & $-0,15858$ & $-0,0525$ & $-0,0772$ & $-0,02233$ & 0,00416 & 0,07443 & 0,03152 & 0,03211 & 0,2125 \\
$\mathrm{~S}(\mathrm{c})$ & 0,05021 & 0 & 0,10608 & 0,08138 & 0,13625 & 0,16274 & 0,23301 & 0,1901 & 0,19069 & 0,37108 \\
\hline
\end{tabular}


According to Table 5, typical values are marked in reverse relative to each other along the diagonal. This indicates that the proportions complement each other. The resulting values were collected throughout the column, and the total standard value was found. The average value was obtained by dividing the total value by 10 , and the value belonging to the $\mathrm{B}$ property (-0.15858), which is the smallest value among these values, was pulled to 0 , which is the starting point. Since this value is negative, 0.15858 has been added to the values of other properties.

The data relating to the obtained scale values were determined and shown on the graph to be seen more clearly. The situation obtained through the data is given in Graph 1 .

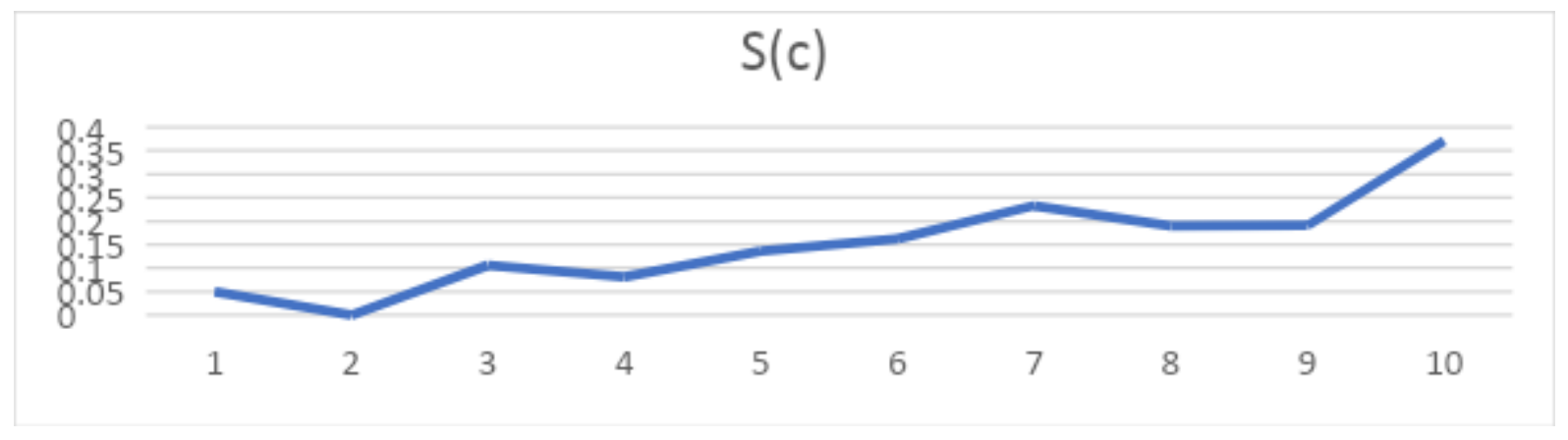

Graph 1. Ranking Judgments of Participants Scale Values

According to Graph 1, the feature with the lowest scale value appears as the most important feature, while the value with the highest scale value appears as the feature that is seen as less important than the others. The feature given in the second row is the most important compared to the other features, and the feature given in the tenth rank is the least important compared to the other features.

The ranking resulting from the findings is given below:

- Being democratic in life

- Thinking that students are different

- Be patient in the education and training process

- Knowledge of the student's past life

- Innovative perspective 
- Paying attention to professional development

- Tendency to lead a loving life

- Not to be prejudiced against any individual

- Having universal values

- To be understanding towards those around you

According to the ranking obtained by the teachers, culturally responsive in education practices that teachers should have the most important feature "of being democratic in the life" is the property compared to others. In contrast, the least important feature "of being sympathetic to the surrounding people" has emerged as a feature.

\section{Discussion and Conclusion}

In this study, the characteristics of culturally responsive teachers and the order of importance of these characteristics were revealed. The first feature of the study is that the teacher is democratic in his life. The characteristics listed in the scope of the research and the ranking of characteristics within the scope of educational pedagogy culturally responsive are different from each other. There may be several cultural causes for this condition. Since Turkey has different socioeconomic levels as a way of life (Albayrak, 2005), teachers face students from different socioeconomic levels. This requires teachers to struggle with one of the differences, the socioeconomic level. However, the multicultural structure of Turkey also requires teachers to cope with differences. For this reason, it can be considered that the most important feature for teachers is democratization. Creating a democratic environment in the classroom will be able to ensure that differences are respected, that students feel comfortable, that problems arising from differences disappear through tolerance, that students think critically, and that communication is free of bias (Büyükkaragöz \& Kesici, 1996; Demirpolat, 1999; Tahiroğlu \& Aktepe, 2015). Ford (2007; cited in Ford \& Kea, 2009) stated that having democratic attitudes and values is an important feature for teachers sensitive to cultural values. These differences will cease to be distinctive thanks to teachers and students who behave equally, equitably, respectfully, and freely in the classroom. For culturally responsive education, first of all, these differences should be prevented from creating discrimination, and students should be able to express themselves comfortably. 
The ability of second-row students to think that they are different is also a feature of high importance in culturally responsive educational practices. It is consistent with the relevant literature (Villegas \& Lucas, 2002; Weinstein, Tomlinson-Clarke \& Curran, 2004; Ford, 2007, cited in Ford \& Kea, 2009). Unlike past education, it is now accepted that the student comes to the school with certain patterns, beliefs, or attitudes instead of coming to the school as a blank sheet. Therefore, each student is different, or the state of being respectful of this diversity, to turn culturally responsive of the differences training is an important point for chance (Gay, 2000; Ladson-Billings, 1999; Pewewardy \& Hammer, 2003; Vonta, 2009). By recognizing that students are different, teachers will consider the differences in the educational environment and manage their educational processes in this context.

The third rank feature is that being patient in the education and training process is also an important teacher characteristic (Çelikten, Şanal, \& Yeni, 2005). In classrooms where differences are experienced, the teacher must continue to work patiently to raise students who respect these differences and are united around universal values. In other research on teacher characteristics, Turkey is also among the important features you need to distinguish between being the teacher of the owner (Moon \& Yurdabak the 2015 Aries, 2010; Hair, Find, the Ethics and \& Kangalgil, 2009; from 2001). Karakelle's (2005) study revealed that being patient is among the ten most effective teacher characteristics. More differences among students in the classroom cause teachers to deal with more problems in today's conditions. In this case, it increases the importance of patience for teachers. In the context of culturally responsive teaching, it also requires teachers who try to meet students' expectations and support them academically to be more patient in managing cultural differences within the classroom.

The feature that appears in the fourth place is in reverse with the relevant literature. The ability to know the past life of the student, which is the most important feature in the context of Education sensitive to cultural values, ranks fourth in the scope of the research. According to Weinstein, Tomlinson-Clarke \& Curran (2004), knowing students ' backgrounds is an important characteristic that teachers should have for a culturally responsive classroom environment. Teachers getting to know the student's culture is important for all students to succeed (Guild, 1994). Culture affects the way of thinking, behavior, and communication (Taylor \& Sobel, 2011). Teachers getting to know the student's culture also means understanding the student's way of thinking, communication 
style and behavior. In this case, it is very important to create a culturally responsive educational environment. Although knowing the student's past life is an important feature that supports the student's academic and social development, the teachers involved in the study evaluated the question from a narrow angle may have caused this feature to fall into the lower ranks. Besides, teachers who do not have an adequate level of knowledge and experience related to education sensitive to cultural values may not be aware of the importance of this feature.

The fifth-place innovative perspective reflects the innovative behavior (Thurlings, Evers \& Vermulen, 2015) feature, which includes the stages of "producing, creating, developing, implementing, promoting, noticing and defining new ideas." Having an innovative perspective is a feature that is necessary to increase students 'learning levels (Eaude, 2011) and facilitates adaptation to changing society (Thurlings, Evers, \& Vermeulen, 2015), and helps respond to students' needs (Hargreaves, 1999). The coming together of students from different cultures in schools has created a new learning environment, which has changed the expectations and needs of students. In order to respond to the academic and social needs of all students and increase their learning levels, it is important to stand out from the traditional point of view and have an innovative point of view.

The characteristics of giving importance to professional development and leading loving lives, which are ranked sixth and seventh, are the characteristics that teachers should have in the teaching profession. The teacher needs to turn the classroom into a learning community when considered within the context of culturally responsive educational practices (Shade, Kelly \& Oberg, 1997). This will allow the teacher to manage their professional development process primarily. Good communication with the environment of the teacher, socialization of students is a situation related to love (Ercan, 2014) and is an important point in educational practices sensitive to cultural values. For this situation to be achieved, the teacher must be optimistic about his environment and loving in his life.

The characteristics of not being prejudiced against any individual in the eighth and ninth place and having universal values are among the important features within the scope of culturally responsive teaching. Despite this, it was ranked lower in the scope of the research. This situation can be interpreted as a teacher with other characteristics might have been thought of as not having prejudices and having universal values. In the same way, being savvy towards the people around him who are in the last place ranks at the bottom can be 
interpreted as why the teacher should already be savvy towards his environment. For example, a teacher with democratic behavior has a peaceful understanding that values different views, is solution-oriented, sensitive to the well-being of others (Sisman, Gules, \& Donmez, 2010). At this point, teachers may have put these features in the last place. Weinstein, Tomlinson-Clarke \& Curran (2004) and Ford (2007; cited in Ford \& Kea, 2009) stated that teachers should be aware of their prejudices to be sensitive to cultural values. According to Banks (1994; cited in Weinstein, Tomlinson-Clarke, \& Curran, 2004), people do "cultural encapsulation" by not going beyond life in a certain area. In other words, they experience cultural isolation. Therefore, prejudices should be aware of and try to get rid of this isolation process.

Educational practices sensitive to cultural values are one of the important priorities in classrooms where there are differences. Because cultural values-sensitive education is a practice that starts from the process of knowledge formation, continues to learn about students ' past lives, create socio-cultural awareness, support positive opinions about differences, use appropriate educational methods that will allow all students to learn, and makes it a priority to include all students (Villegas \& Lucas, 2002). Given this constantly repeating process, it is expected that teachers also have various characteristics within the framework of teaching that is culturally responsive. These characteristics are evaluated in the context of culturally responsive pedagogy, attentive, empathetic, reflective of beliefs and attitudes towards other cultures, and cultures to learn about features such as being reflective of their culture reveals (Rychly \& graves, 2012). Although these features are superficially stated, various details are revealed when examined in depth.

Culturally responsive pedagogy studies at this point, the teachers, the knowledge of the past life of the student, the students will be aware of the differences, the students within the class to be biased against the formation of stereotypes and to be an obstacle to innovative and visionary perspective, students and parents understanding of universal values around mergers, professional development, managing the process, creating a democratic environment, have high expectations, and these expectations should have access to academically to be patient asserts that processing features (Gay, 2002; Johnson, 2014; Ladson-Billings, 2009; Villegas \& Lucas, 2002; Weinstein, Tomlinson-Clarke \& Curran, 2004; Ford, 2007, cited in Ford \& Kea, 2009). These features are close to the ones selected in the research. 
When examined under teachers' views, Turkey, in particular, are culturally sensitive of a teacher; Democratic, who thinks that his students are different and knows the importance of these differences, has high expectations with his students' academic and social lives and processes this expectation patiently, knows the past lives of his students, attaches importance to developing himself with an innovative perspective and this development is within the professional development process. A developing model tends to lead a loving life in both business and private life, is free from prejudices, has universal values, and understands its people. It is thought that the teacher with these characteristics can realize culturally responsive educational practices.

When examined in general, culturally responsive teacher characteristics may differ by being culturally influenced in various countries. However, by examining the order of importance of the obtained features, it can be ensured that these characteristics of the teachers in the education system are developed, or the teacher candidates gain these characteristics. With the spread of culturally responsive educational practices, the importance of these features will become more evident. Developing culturally values sensitive teacher characteristics will increase educational practices in schools (Ellerbrock, Cruz, Vásquez, \& Howes, 2016; Lucas \& Villegas, 2013; Yuan, 2017). The importance of culturally responsive education $\mathrm{s}$ will become more pronounced with increasing differences and more coexistence of these differences. Culturally responsive education is an important point for students to have universal values, live their own culture with a critical and reflective perspective, and build a society in this way. The findings of the study within the context of the specified properties for the teachers through in-service training, and teachers to equip students through their curriculum, according to the relevant literature for the ranking of the features of some of the features to be performed again because it is different on different teachers of the teachers were culturally responsive, and it is suggested to raise awareness at the point of educational practices. 
Ethical Approval: This research was carried out with the permission of Pamukkale University Social and Humanities Research and publication Ethics Board Decision No. 08-2 dated 23/09/2020

Conflict Interest: There is no conflict of interest.

Authors' Contributions: The first author contributed to creating the theoretical framework, data analysis, findings, conclusion, and discussion. The second author contributed to creating the theoretical framework, findings, conclusion and discussion, and recommendations.

\section{References}

Akbaş, O. (2008). Değer eğitimi akımlarına genel bir bakış. Değerler Eğitimi Dergisi, 6(16), 9-27.

Albayrak, A. S. (2005). Türkiye'de illerin sosyoekonomik gelişmişlik düzeylerinin çok değişkenli istatistik yöntemlerle incelenmesi. ZKÜ Sosyal Bilimler Dergisi, 1(1), 153-177.

Ay, Ş., \& Yurdabakan, İ. (2015). Öğretmen adaylarına göre etkili öğretmen özellikleri ve bu özellikler açısından öz-yeterlik algıları. Mehmet Akif Ersoy Üniversitesi Eğitim Fakültesi Dergisi (33), 148-166.

Banks, J. A. (1994). An introduction to multicultural education. Boston: Allyn \& Bacon.

Banks, C. A. M. \& Banks, J. A. (1995) Equity pedagogy: An essential component of multicultural education, Theory into Practice, 34 (3), 152-158.

Bozgeyikli, H., Toprak, E., \& Derin, S. (2016). Öğretmen adaylarinin mesleki değer algilarinin ölçeklenmesi. Emek ve Toplum, 5(11), 204-225.

Büyükkaragöz, S., \& Kesici, Ş. (1996). Öğretmenlerin hoşgörü ve demokratik tutumları. Ĕ̆itim Yönetimi, 2(3), 353-365.

Çelikten, M., Şanal, M., \& Yeni, Y. (2005). Öğretmenlik mesleği ve özellikleri. Sosyal Bilimler Enstitüsü Dergisi, 19(2), 207-237.

Demirpolat, A. O. (1999). Demokrasi ve demokratik eğitim. Kuram ve Uygulamada Egitim Yönetimi Dergisi, 5(2), 229-248. 
Eaude, T. (2011). Compliance or innovation? Enhanced professionalism as the route to improving learning and teaching. Education Review, 23(2), 49-57.

Ercan, R. (2014). Öğretmenlerde çocuk sevgisi. Turkish Studies, 9(8), 435-444.

Erden, M. (2001). Öğretmenlik meslĕgine giriş. İstanbul: Al $\neg$ kım Yayınları.

Ellerbrock, C. R., Cruz, B. C., Vásquez, A., \& Howes, E. V. (2016). Preparing culturally responsive teachers: Effective practices in teacher education. Action in Teacher Education, 38(3), 226-239.

Ford, D. Y., \& Kea, C. D. (2009). Creating culturally responsive instruction: For students' and teachers' sake. Focus on Exceptional Children.41(9), 1-17.

Ford, D. Y. (2010). Culturally Responsive Classrooms: Affirming Culturally Different Gifted Students, Multicultural Issues, 33(1), 50-53.

Gay, G. (2000). Culturally responsive teaching. New York: Teachers College Press.

Gay, G. (2002). Preparing for culturally responsive teaching. Journal of Teacher Education, 53(2), 106-116.

Gay, G. (2018). Culturally responsive teaching: Theory, research, and practice. (3rd Ed.). Teachers College Press

Guild, P. (1994). The culture/learning style connection, Educational Leadership, 51(8), 1621.

Hargreaves, D. (1999). Schools and the future: The key role of innovation in innovating schools. In innovation Schools (s. 45-57). Paris: OECD PublicationsEnvironment, Prentice Hall International Inc., London.

Jarosinski, T. (2018). Culturally responsive teaching practices for educators of culturally and linguistically diverse students. Education and Human Development, Master's Theses. 1107. The College at Brockport: State University of New York https://digitalcommons.brockport.edu/ehd_theses/1107

Johnson, L. (2014). Culturally responsive leadership for community Empowerment. Multicultural Education Review, 6(2), 145-170. doi: https://doi.org/10.1080/2005615X.2014.11102915

Karakelle, S. (2005). Öğretmenlerin etkili öğretmen tanımlarının etkili öğretmenlik boyutlarına göre incelenmesi, Eğitim ve Bilim, 30(135), 1-10. 
Karasar, N. (2000). Bilimsel araştırma yöntemi (10. Baskı b.). Ankara: Nobel Yayın Dağıtım.

Karataş, K. (2020). Kültürel değerlere duyarlı öğretmen ölçeği geçerlik ve güvenirlik çalışması, Elektronik Sosyal Bilimler Dergisi, 19(76), 1761 - 1775.

Karataş, K., \& Oral, B. (2017). Kültürel değerlere duyarlı eğitime hazırbulunuşluk ölçeği. Eğitim Bilimleri Araştırmaları Dergisi, 7(2), 257-268.

Koç, A. (2010). Din kültürü ve ahlâk bilgisi öğretmenlerinin yeterlikleri. Değerler Eğitimi Dergisi, 8(19), 107-149.

Kotluk, N., \& Kocakaya, S. (2018a). Türkiye için alternatif bir anlayış: Kültürel değerlere duyarlı eğitim. YYÜ Eğitim Fakültesi Dergisi, 15(1), 749-789.

Kotluk, N. \& Kocakaya, S. (2018b). Culturally relevant/responsive education: What do teachers think in Turkey, Journal of Ethnic and Cultural Studies, 5(2), 98-117.

Kotluk, N. \& Kocakaya, S. (2017). Teachers' culturally relevant teaching self-efficacy beliefs in Turkey: A scale development study. 2nd Eurasian Conference on Language and Social Sciences (ECLSS 2017), September 29 -October 1, 2017, Antalya, Turkey.

Ladson-Billings, G. (2009). The dream keepers: Successful teachers of African American children. San Francisco: Wiley.

Ladson-Billings. G. (1999). Preparing teachers for diverse student populations: A critical race theory perspective, Review of Research in Education, 24(1), 211-247.

Lazar, A. M., Edwards, P. A. \& McMillon, G. T. (2012). Bridging literacy and equity: the essential guide to social equity teaching. New York, NY: Teachers College Press

Lucas, T., \& Villegas, A. M. (2013). Preparing linguistically responsive teachers: Laying the foundation in pre-service teacher education. Theory into Practice, 52(2), 98-109.

MEB. (1973). Milli Eğitim Temel Kanunu. Resmi Gazete, 24.6.1973, Say1, 14574. June 14, 2020 MEB Mevzuat: https://www.mevzuat.gov.tr/MevzuatMetin/1.5.1739.pdf

Nayir, F. (2019). Kültürel değerlere duyarlı öğretmen rolleri ölçeğinin geliştirilmesi, Turkish Studies Educational Sciences, 14(I6), 3273-3292.

Nieto, S. (2002). Language, culture, and teaching: Critical perspectives for a new century. Mahway, NJ: Lawrence Erlbaum. 
Pewewardy, C., \& Hammer, P. C. (2003). Culturally responsive teaching for American Indian students. ERIC Digest, 1-9.

Rychly, L., \& Graves, E. (2012). Teacher characteristics for culturally responsive pedagogy. Multicultural Perspectives, 14(1), 44-49. doi: https://doi.org/10.1080/15210960.2012.646853

Saçlı, F., Bulca, Y., Demirhan, G., \& Kangalgil, M. (2009). Beden eğitimi öğretmenlerinin kişisel nitelikleri. Spor Bilimleri Dergisi, 20(4), 145-151.

Shade, B. J., Kelly, C., \& Oberg, M. (1997). Creating culturally responsive classrooms. Washington DC: American Psychological Association.

Şahin, A. (2011). Öğretmen algılarına göre etkili öğretmen davranışları. Ahi Evran Üniversitesi Ĕ̆itim Fakültesi Dergisi, 12(1), ss.239-259.

Şişman, M., Güleş, H., \& Dönmez, A. (2010). Demokratik bir okul kültürü için yeterlilikler çerçevesi. Uşak Üniversitesi Sosyal Bilimler Dergisi, 3(1), 167-182.

Tahiroğlu, M., \& Aktepe, V. (2015). Değerler eğitimi yaklaşımlarına göre geliştirilen etkinliklerin demokratik algı ve davranışlar üzerine etkisi. Değerler Eğitimi Dergisi, 12(30), 309-345.

Taylor, S.V. ve Sobel, D.M. (2011). Culturally responsive pedagogy: Teaching like our students lives matter, Howard Hause: Emerald Group Publishing Limited.

Thurlings, M., Evers, A. T., \& Vermeulen, M. (2015). Toward a model of explaining teachers' innovative behavior: a literature review. Review of Educational Research, 85(3), 430-471. doi: 10.3102/00346543145579

Turgut, M. F., \& Baykul, Y. (1992). Ölçekleme teknikleri. Ankara: ÖSYM Yayınları.

UNHCR. (2019, July). UNHCR BM Mülteci örgütü. December 6, 2019 UNHCR Türkiye İstatistikleri: https://www.unhcr.org/tr/unhcr-turkiye-istatistikleri

Villegas, A. M. \& Lucas, T. (2002). Preparing culturally responsive teachers. Journal of Teacher Education, 53(1), 20-32. doi:10.1177/0022487102053001003.

Villegas, A. M., \& Lucas, T. (2007). The culturally responsive teacher. Educational Leadership, 64(6), 28-33.

Weinstein C., Tomlinson-Clarke S., \& Curran M. (2004). Toward a conception of culturally responsive classroom management. Journal of Teacher Education, 55(1), 25-38. 
Weinstein, C., Curran, M., \& Tomlinson-Clarke, S. (2003). Culturally responsive classroom management: awareness into action. Theory into Practice, 42(4), 269-276.

Vonta, T. (2009). Building teacher's capacity for quality education - Condition for inclusiveness. Inter-Network Conference (s. 156-167). Spain: LJUBLJANA Conference Proceedings.

Yuan, H. (2017). Developing culturally responsive teachers: Current issues and a proposal for change in teacher education programs. World Journal of Education, 7(5), 66-78.

Yıldırım, A., \& Şimşek, H. (2013). Sosyal bilimlerde nitel araştırma yöntemleri. Seçkin Yayınc1lik. 